\title{
Prediction of Drug-Target Binding Kinetics for Flexible Proteins by Comparative Binding Energy Analysis
}

\author{
Ariane Nunes-Alves, ${ }^{*, \dagger, \dagger}$ Fabian Ormersbach, ${ }^{\dagger}$ and Rebecca C. Wade, ${ }^{*,+,, \uparrow}$ \\ $\dagger$ Heidelberg Institute for Theoretical Studies (HITS), Schloß-Wolfsbrunnenweg 35, 69118 \\ Heidelberg, Germany \\ $\ddagger$ Center for Molecular Biology (ZMBH), DKFZ-ZMBH Alliance, Heidelberg University, Im \\ Neuenheimer Feld 282, 69120 Heidelberg, Germany \\ \Interdisciplinary Center for Scientific Computing (IWR), Heidelberg University, Im \\ Neuenheimer Feld 205, Heidelberg, Germany \\ E-mail: ariane.nunes-alves@h-its.org; rebecca.wade@h-its.org
}

\begin{abstract}
There is growing consensus that the optimization of the kinetic parameters for drug-protein binding leads to improved drug efficacy. Therefore, computational methods have been developed to predict kinetic rates and to derive quantitative structurekinetic relationships (QSKRs). Many of these methods are based on crystal structures of ligand-protein complexes. However, a drawback is that each protein-ligand complex is usually treated as having a single structure. Here, we present a modification of COMparative BINding Energy (COMBINE) analysis, which uses the structures of proteinligand complexes to predict binding parameters. We introduce the option to use multiple structures to describe each ligand-protein complex into COMBINE analysis and apply this to study the effects of protein flexibility on the derivation of dissociation rate
\end{abstract}


constants $\left(\mathrm{k}_{\text {off }}\right)$ for inhibitors of p38 mitogen-activated protein (MAP) kinase, which has a flexible binding site. Multiple structures were obtained for each ligand-protein complex by performing docking to an ensemble of protein configurations obtained from molecular dynamics simulations. Coefficients to scale ligand-protein interaction energies determined from energy-minimized structures of ligand-protein complexes were obtained by partial least squares regression and allowed the computation of $\mathrm{k}_{\text {off }}$ values. The QSKR model obtained using single, energy minimized crystal structures for each ligand-protein complex had a higher predictive power than the QSKR model obtained with multiple structures from ensemble docking. However, the incorporation of protein-ligand flexibility helped to highlight additional ligand-protein interactions that lead to longer residence times, like interactions with residues Arg67 and Asp168, which are close to the ligand in many crystal structures, showing that COMBINE analysis is a promising method to design leads with improved kinetic rates for flexible proteins.

\section{Introduction}

The realization that drug binding kinetic rates can be key determinants of drug efficacy in vivo $^{1-3}$ has led to high interest in the development of computational methods to estimate the drug-target dissociation rate constant $\left(\mathrm{k}_{o f f}\right)$ or its inverse, the residence time $\left(\tau=1 / \mathrm{k}_{o f f}\right)$. A range of computational methods have been proposed to estimate $\mathrm{k}_{\text {off }}$ values at low to moderate computational cost,${ }^{4}$ and these may facilitate rational drug design. On one hand, there are methods based on molecular dynamics (MD) simulations, such as $\tau$ RAMD $^{5}$ and scaled MD, ${ }^{6}$ in which a force or energy bias is added to the system, thereby allowing relative $\mathrm{k}_{\text {off }}$ values for a set of compounds to be estimated within a few days. Other methods, such as weighted ensemble, ${ }^{7,8}$ allow absolute $\mathrm{k}_{\text {off }}$ values to be estimated at a higher computational

cost. On the other hand, there are chemometric methods such as COMparative BINding Energy (COMBINE) analysis ${ }^{9}$ and Volsurf, ${ }^{10}$ which require an experimental dataset with at least tens of ligands for training a system-specific model, but then allow one to estimate $\mathrm{k}_{\text {off }}$ 
values in seconds or minutes by using chemical descriptors of the ligand or of the structure of the ligand-protein complex.

Here, we used COMBINE analysis ${ }^{11}$ to predict $\mathrm{k}_{\text {off }}$ values for ligand-protein complexes. Among chemometric methods, COMBINE analysis has the advantages of using the full information available from experimental structures of ligand-protein complexes and identifying specific protein residues that affect the computed parameters. In COMBINE analysis, the interaction energies (E) between the ligand and each protein residue computed from the structure of the complex using a classical molecular mechanics force field can be decomposed:

$$
E=\sum_{k=1}^{n_{p}} E_{k}^{v d W}+\sum_{k=1}^{n_{p}} E_{k}^{\text {elec }}
$$

where $\mathrm{E}^{v d W}$ and $\mathrm{E}^{\text {elec }}$ designate van der Waals and electrostatic interaction energies, respectively, $\mathrm{n}_{p}$ is the total number of protein residues and $\mathrm{k}$ is the index of residues. Then, $n$ interaction energies $\left(\mathrm{E}_{i}\right)$, which have standard deviation over a defined threshold and are expected to contribute the most to the differences in $\mathrm{k}_{\text {off }}$ values, are selected and scaled by coefficients or weights $\left(w_{i}\right)$ obtained from partial least squares (PLS) regression for a training set:

$$
\log k_{o f f} \approx \sum_{i=1}^{n} w_{i} E_{i}+C
$$

where $\mathrm{i}$ is the index of the selected interaction energies, and $\mathrm{C}$ is a constant that accounts for factors not included in $E_{i}$, such as covalent energy terms, entropy gain or solvation of the ligand during the (un)binding process. First, eq. 2 is used with computed $\mathrm{E}_{i}$ values and experimental $\mathrm{k}_{\text {off }}$ values to allow the assignment of $\mathrm{w}_{i}$ and $\mathrm{C}$ values. Once known, the $\mathrm{w}_{i}$ and $\mathrm{C}$ values are employed to compute $\mathrm{k}_{\text {off }}$ values for other similar complexes. COMBINE analysis was recently used to predict $\mathrm{k}_{\text {off }}$ values for inhibitors of heat shock protein 90 (HSP90) and HIV-1 protease, ${ }^{9}$ achieving good predictive power (coefficient of determination for cross-validation, $\mathrm{Q}^{2}$, of 0.69 and 0.70 , respectively). COMBINE analysis was used 
originally to predict inhibitory activities for complexes of the human synovial fluid phospholipase A2 with small molecules. ${ }^{11}$ Moreover, it has already been applied to predict affinities or inhibitory activities for complexes of proteins with small molecules, ${ }^{12,13}$ peptides ${ }^{14}$ and other proteins. ${ }^{15}$

One of the potential drawbacks of COMBINE analysis is that the ligand-protein complex is represented by a single energy minimized structure, which limits the representation of protein flexibility and ligand binding modes. Sometimes ligands or side chains have more than one possible configuration in a single crystal structure. Moreover, ligand-protein complexes are flexible in in vivo conditions, so considering this flexibility might be expected to improve quantitative structure-kinetic relationship (QSKR) models or quantitative structure-activity relationship (QSAR) models derived by COMBINE analysis.

Different strategies can be used to represent protein-ligand complexes flexibility. For instance, a set of protein configurations from crystal structures ${ }^{16}$ or nuclear magnetic resonance can be employed. Representative sets of protein configurations can also be obtained from computational methods, such as MD simulations, ${ }^{17-20}$ machine learning ${ }^{21,22}$ or elastic network models. ${ }^{23}$ The representation of protein flexibility using ensembles of configurations was shown to be beneficial in docking, leading to improved results in the prediction of binding affinities $^{18}$ and in the identification of true binders in a large set of small molecules. ${ }^{16,19}$

The aim of this work was to extend the COMBINE analysis method to allow the use of an ensemble of structures to represent one ligand-protein complex, in order to incorporate the effects of structural flexibility in the predictions of binding parameters. Two COMBINE analysis models were built to predict $\mathrm{k}_{\text {off }}$ values, one using one energy minimized crystal structure to represent each ligand-protein complex, and one using 10 structures from ensemble docking to represent each ligand-protein complex. The ensemble of protein configurations for docking was obtained from MD simulations. p38 mitogen-activated protein (MAP) kinase, for which $\mathrm{k}_{\text {off }}$ values are available for a number of complexes, was selected as a model system. This choice was motivated by the fact that there is a region (residues 170 
to 184 in PDB $1 \mathrm{KV}^{24}$ ) close to the binding site that is missing in many crystal structures, which suggests that it is disordered and flexible. Moreover, due to its location, this region may have transient interactions with inhibitors, playing a role in ligand binding. Type-II inhibitors, which occupy an allosteric pocket close to the ATP binding site, ${ }^{25}$ were selected for this work due to the spread of experimental $\mathrm{k}_{\text {off }}$ values and the availability of crystal structures. They occupy a pocket created by a conformational change in the conserved amino acid sequence Asp-Phe-Gly (DFG motif, residues 168-170) in the activation loop, and bind to the out (inactive) conformation of the DFG motif of p38 MAP kinase. ${ }^{25}$

\section{Computational methods}

\section{$2.1 \quad$ Dataset}

The full dataset for the COMBINE analysis model was composed of 33 inhibitors of p38 MAP kinase (Figure S1, Table S1). These inhibitors were chosen based on the availability of (i) experimental $\mathrm{k}_{\text {off }}$ values ${ }^{24,26-29}$ (Table $\mathrm{S} 2$ ); and (ii) experimental structures of the inhibitor bound to p38 MAP kinase or to other kinases in the DFG-out conformation (Table S2), or similarity to inhibitors with experimental structures available for the complex. The dataset was split into a training set and a test set, with 22 and 11 inhibitors, respectively. The dataset was ranked according to $\mathrm{k}_{\text {off }}$ values and every third ligand was assigned to the test set. Using this procedure, ligands $3,5,6,12,14,16,21,24,28,34$ and 35 were selected to be part of the test set (Table S2). Additional tests were performed with three other test sets selected similarly, namely: ligands 1, 2, 8, 15, 17, 22, 26, 27, 31, 32 and 36; ligands 7, $9,11,13,18,20,23,25,29,30$ and 33 ; or ligands $3,5,12,14,16,21,24,34$ and 35 . The results were similar (data not shown). 


\subsection{Parametrization of COMBINE analysis model}

First, two sets of structures for the dataset were modeled and used to derive COMBINE analysis models (sections 2.4 and 2.5). Then, structures were energy minimized (section 2.6). After energy minimization, interaction energy components for the training set and test set were obtained using the COMBINE software ${ }^{30}$ and the AMBER ff14SB force field ${ }^{31}$ to describe parameters for bonded and non-bonded interactions. Electrostatic interactions were computed using a uniform dielectric constant of 4 . Tests were performed with a distance dependent dielectric constant for which the predictive performance was similar or slightly less good (data not shown). Interaction energy components that had a standard deviation greater than the cutoff value of $0.25 \mathrm{kcal} / \mathrm{mol}$ were selected for regression. Then, coefficients or weights to scale the ligand-protein interaction energies were obtained by COMBINE analysis $^{11}$ using partial least squares regression ${ }^{32}$ (section 2.3). Up to 10 latent variables were tested to decompose the data in partial least squares regression.

\subsection{Modification of COMBINE software to use multiple structures to represent one ligand-protein complex}

Previously, COMBINE analysis has been performed using one structure to represent one protein-ligand complex and estimate one response (in this case, log $\mathrm{I}$, where I can be $\mathrm{k}_{\text {off }}$, binding affinity, inhibitory activity or any other parameter related to ligand-protein interactions). Here, the COMBINE software ${ }^{30}$ was modified to retrieve an average response using $\mathrm{N}$ structures for each ligand-protein complex. Multiple structures for one complex were obtained using ensemble docking (details in section 2.5). Each structure is treated independently during the regression step to obtain weights for interaction energies. The responses obtained from the $\mathrm{N}$ structures are averaged, resulting in one final response for the complex. The average can be arithmetic or exponential. 
Previously: ${ }^{11}$

$$
(\log I)^{c o m p}=\log I^{1}
$$

where $(\log \mathrm{I})^{c o m p}$ is the prediction for the response variable and $\log \mathrm{I}^{1}$ is the prediction made using 1 structure to represent the ligand-protein complex.

In the ensemble method introduced here, exponential (eq. 4) or arithmetic averages (eq. 5) can be used to obtain one response variable from $N$ structures:

$$
\begin{gathered}
(\log I)_{\text {exp }}^{c o m p}=-\log \frac{1}{N} \sum_{j=1}^{N} e^{-\log I^{j}} \\
(\log I)_{\text {arit }}^{c o m p}=\frac{1}{N} \sum_{j=1}^{N} \log I^{j}
\end{gathered}
$$

where $\mathrm{j}$ is the index of the structure used. Eqs. 4 and 5 give the same result as eq. 3 for $\mathrm{N}=1$ or for $\mathrm{N}$ identical structures representing one ligand-protein complex. The exponential average proposed is based on previous studies using protein conformational averaging for an adapted linear interaction model ${ }^{18}$ and the implicit ligand theory. ${ }^{33}$ Here, $(\log \mathrm{I})_{\text {arit }}^{\text {comp }}$ and $(\log \mathrm{I})_{\text {exp }}^{c o m p}$ are the total computed $\log \mathrm{I}$ for one ligand-protein complex, while $\log \mathrm{I}^{j}$ is the $\log$ I computed from weighted interaction energy terms for structure $\mathrm{j}$.

Two new parameters were added in the COMBINE analysis input file: $\mathrm{N}$, the number of structures to describe one ligand-protein complex, and the averaging scheme to be used (arithmetic or exponential). The cross-validation part of the COMBINE software was also modified so that all structures of one ligand-protein complex are removed from the training set when necessary. 


\subsection{Modeling of protein-ligand structures using data from X-ray crystallography}

Two sets of structures were used to derive COMBINE analysis models. In one set, each complex was represented using one structure, usually a crystal structure, described in this section. In the other set, each complex was represented using 10 structures from ensemble docking (section 2.5).

Crystal structures of protein-ligand complexes retrieved from the Protein Databank (PDB) were used after removal of water and other crystallization molecules. Ligands 1 , 2, 16, 25, 32 and 33 had crystal structures available (PDBs 1KV1, ${ }^{24} 1 \mathrm{KV} 2,{ }^{24} 3 \mathrm{HV} 6,{ }^{34}$ $3 \mathrm{HEC},{ }^{35}{ }^{2} \mathrm{YIW}^{27}$ and $2 \mathrm{YIS},{ }^{27}$ respectively, Table S2). Incomplete regions were built using homology modeling with Modeller ${ }^{36}$ and the structure from PDB file $1 \mathrm{WBV}^{37}$ as a reference. This structure was chosen because it is fully resolved and has good resolution $(2 \AA)$. For each structure, 20 models were built and the one with the lowest DOPE score was selected. Incomplete side chains were built with Modeller. Hydrogens were added using pdb2pqr ${ }^{38,39}$ at $\mathrm{pH} 7.2$ for the protein and Babel ${ }^{40}$ for the ligands. All protein structures had a net charge of -7 e.

Ligands 3-15, 17-24, 26-31 and 34-36 had no crystal structures in complex with p38 MAP kinase available. A ligand search in KLIFS, ${ }^{41,42}$ a structural database for kinases, using SMILES showed that ligands 20-24 and 26-31 had crystal structures available in complexes with other kinases (PBDs 4RZW, ${ }^{43} 3 \mathrm{~F} 82,{ }^{44} 3 \mathrm{QRI},{ }^{45} 3 \mathrm{LQ} 8,{ }^{46}$ 5IA5, ${ }^{47}$ 3EFL, 3GP0, 6FNI, ${ }^{48}$ 4U0I, ${ }^{49} 4 \mathrm{RT}^{50}$ and $4 \mathrm{ASE},{ }^{51}$ respectively, Table S2). Complexes with p38 MAP kinase for these ligands were built using the binding modes in the available crystal structures as references. Complexes with p38 MAP kinase for ligands 3-15, 17-18 and 34-36 were built using the binding mode of ligand 16 (PDB 3HV6) as a reference. Ligand superimposition was performed using a custom script built using Python 3.8 and the packages RDkit 2020.03.3 $3^{52}$ and MDAnalysis 1.0.0 $0^{53,54}$ (details and validation using $\operatorname{ligRMSD}{ }^{55}$ are given in section S2). 
The ligand geometry was built using Molden $^{56}$ and energy minimized using AMBER $2016^{57}$ and the AMBER ff14SB force field ${ }^{31}$ if crystal structures were not available.

\subsection{Modeling of protein-ligand structures using ensemble docking}

A configurational ensemble was generated for p38 MAP kinase bound to ligand 16. An ensemble from the apo protein was not tested, as a previous study showed that ensembles generated from apoprotein structures can have occluded binding sites. ${ }^{18}$ The structure of the ligand-protein complex was energy minimized, and a molecular dynamics simulation was run for 1200 nanoseconds (see details in section 2.6). The ensemble was built using 10 configurations (excluding the ligand) collected along the trajectory at time intervals of 80 nanoseconds for the last 800 nanoseconds of simulation. For each configuration in the ensemble, 20 ligand poses were generated by docking, and the top pose (irrespective of the binding mode) was selected, resulting in a total of 10 ligand-protein structures for each ligand.

Docking to the ensemble was performed with AutoDock Vina. ${ }^{58}$ Parameters for docking were optimized by redocking and cross-docking (section 3.2), resulting in the choice of an exhaustiveness level of 8 and a cubic grid with a spacing of $0.375 \AA$ and 70 points along each edge centered in the known binding site. Bond rotations were allowed in ligands, while the protein structures were kept rigid.

\subsection{Force field and simulation details}

AMBER $2016^{57}$ was used for energy minimization and MD simulations. Parameters to describe the protein and the ligand were obtained from the AMBER ff14SB force field ${ }^{31}$ and the General AMBER Force Field (GAFF) ${ }^{59}$ respectively. RESP ${ }^{60,61}$ partial atomic charges for ligands were obtained using electrostatic potentials from quantum mechanical calculations performed in GAMESS ${ }^{62}$ using single-point calculations (HF/6-31G**) after energy minimization of the ligand structure (HF/6-31G). 
Energy minimization of ligand-protein complexes was performed in two steps. In the first step, a harmonic restraint with a force constant of $100 \mathrm{kcal} /\left(\mathrm{mol} \AA^{2}\right)$ was applied to the positions of the heavy atoms. In the second step, no positional restraints were used. For each step of energy minimization, 1000 steps of the steepest descent algorithm followed by 4000 steps of the conjugate gradient algorithm were applied. Energy minimization was performed using implicit solvent. The generalized Born (GB) approximation as implemented in the GBn model ${ }^{63}$ was used. The nonpolar contribution was calculated using the LCPO model $^{64}$ to compute the surface area and a surface tension of $0.005 \mathrm{kcal} /\left(\operatorname{mol} \AA^{2}\right) .{ }^{65}$

MD simulations to obtain the configurational ensemble were carried out at $300 \mathrm{~K}$ with a 4 femtosecond time-step, which was possible due to the use of the hydrogen mass repartitioning method. ${ }^{66}$ The structure of ligand 16 bound to p38 MAP kinase from PDB $3 \mathrm{HV} 6^{34}$ was used after removal of crystallization cosolute molecules (waters were maintained). Missing regions and residues were modeled as described previously (section 2.4). Hydrogens were added using pdb2pqr ${ }^{38,39}$ at $\mathrm{pH} 7.2$ for the protein and Babel $^{40}$ for the ligand. The complex was solvated in a periodic box of TIP3P water molecules ${ }^{67}$ with a distance of $15 \AA$ from the solute to the box edge using tleap. 73 sodium ions and 66 chloride ions were added to achieve neutrality and an approximate ionic strength of $150 \mathrm{mM}$. The system was energy minimized with 1000 steps of the steepest descent algorithm followed by 1000 steps of the conjugate gradient algorithm, with restraints of $100 \mathrm{kcal} /\left(\mathrm{mol} \AA^{2}\right)$ on the heavy atoms of the protein and the ligand. The system was heated in cycles of 100-picosecond simulations with gradual temperature increases $(10,50,150$ and $300 \mathrm{~K})$ using the Berendsen thermostat. ${ }^{68}$ Then, the pressure was adjusted to $1 \mathrm{~atm}$ with the Berendsen barostat ${ }^{68}$ in a 400-ps simulation. The 100 $\mathrm{kcal} /\left(\mathrm{mol} \AA^{2}\right)$ restraints were gradually removed in cycles of 500-picosecond simulations (50, 10,5 and $\left.1 \mathrm{kcal} /\left(\operatorname{mol} \AA^{2}\right)\right)$. Then, for production MD simulations, the Langevin thermostat was used to keep the temperature at $300 \mathrm{~K}$, and the Monte Carlo barostat was used to keep the pressure at 1 bar (NPT ensemble). The configurational ensemble obtained from the structure of ligand 16 bound to p38 MAP kinase was used for docking all the ligands in the 
dataset.

\subsection{Sequence alignment}

Sequence alignment of p38 MAP kinase with other human kinases was performed to validate the functional role of the residues identified in the COMBINE analysis. Protein sequences were obtained from UniProt ${ }^{69}$ and pairwise sequence alignment was performed using needle. ${ }^{70,71}$

\section{Results}

\subsection{COMBINE analysis using one crystal structure to represent one ligand-protein complex}

We first made a model representing the protein as one structure to use it as a reference to assess the usefulness of incorporating protein flexibility in COMBINE analysis. Therefore, one energy-minimized structure from X-ray crystallography was used to represent each ligandprotein complex and obtain interaction energies. Using COMBINE analysis, 348 electrostatic and 348 van der Waals interaction energies for each of the 22 p38 MAP kinase inhibitors in the training set were calculated. These interaction energies correspond to the 348 residues in the protein. Then the interaction energies which had a standard deviation greater than the specified cutoff value were selected to remove energy terms that may not contribute to the differences in $\mathrm{k}_{\text {off }}$ values. A cutoff value of $0.25 \mathrm{kcal} / \mathrm{mol}$ was used, since it resulted in better models in a previous study, ${ }^{9}$ resulting in the selection of 36 van der Waals interaction energies and 14 electrostatic interaction energies (Figure S2). Next, the weights of these 50 interaction energies for different numbers of latent variables were determined using PLS regression to correlate the interaction energies with the experimental $\log \mathrm{k}_{\text {off }}$ values (Figure 1A). The coefficients of determination $\left(\mathrm{R}^{2} \operatorname{tr}\right.$ and $\mathrm{Q}^{2}$ for the training and cross-validation 
sets, respectively), the average absolute errors (AAEtr and AAEv for the training and crossvalidation sets, respectively) and the root mean squared errors (RMEtr and RMEv for the training and cross-validation sets, respectively) were calculated using different numbers of latent variables (Tables 1 and S4; equations given in section S1). The model with two latent variables was chosen, since it presented the highest $\mathrm{Q}^{2}$ value, 0.75 , when the leave-one-out method was used for cross-validation (Table S4). The AAEv and RMEv values were 0.68 log $\mathrm{s}^{-1}$ and $0.75 \log \mathrm{s}^{-1}$, respectively, for the leave-one-out method for cross-validation. Moreover, the $\mathrm{Q}^{2}$, AAEv and RMEv values were similar for the different cross-validation methods used (Table 1), showing that the model with two latent variables is consistent. The decrease in $\mathrm{Q}^{2}$ when moving from the leave-one-out method to the leave-two-out and leave-three-out methods was expected, since fewer structures were used in the training set in the latter. This model presented a $\mathrm{R}^{2} \operatorname{tr}$ of 0.86 , showing it could successfully fit the training set (Figure 1B, Table S4). The coefficient of determination for the test set $\left(\mathrm{R}^{2}\right.$ te) was 0.79 (Figure $1 \mathrm{~B}$, Table 1), showing this model had high predictive power.

Table 1: Statistical measures of the validation and test sets for COMBINE analysis models derived for $\log \mathrm{k}_{\text {off }}$ of p38 MAP kinase inhibitors. $\mathrm{Q}^{2}, \mathrm{R}^{2}$ te: coefficient of determination of the cross-validation and test sets; AAEv, AAEte: average absolute error of the crossvalidation and test sets (in $\log \mathrm{s}^{-1}$ ); RMEv, RMEte: root mean squared error of the crossvalidation and test sets (in $\log \mathrm{s}^{-1}$ ).

\begin{tabular}{lcccccc}
\hline & \multicolumn{3}{c}{ single $^{a}$} & \multicolumn{3}{c}{ ensemble $^{b}$} \\
cross-validation set & $\mathrm{Q}^{2}$ & AAEv & RMEv & $\mathrm{Q}^{2}$ & AAEv & RMEv \\
\hline leave-one-out (LOO) & 0.75 & 0.68 & 0.75 & 0.70 & 0.68 & 0.82 \\
leave-two-out (L2O) & 0.72 & 0.68 & 0.79 & 0.67 & 0.70 & 0.85 \\
leave-three-out (L3O) & 0.65 & 0.74 & 0.88 & 0.62 & 0.74 & 0.92 \\
\hline test set & $\mathrm{R}^{2}$ te & AAEte & RMEte & $\mathrm{R}^{2}$ te & AAEte & RMEte \\
\hline & 0.79 & 0.54 & 0.64 & 0.72 & 0.65 & 0.74 \\
\hline
\end{tabular}

${ }^{a}$ One structure per ligand-protein complex, two latent variables. ${ }^{b}$ Ten structures per ligand-protein complex, one latent variable.

The interaction energies with the highest weights were the van der Waals interaction energies of the inhibitors with residues Lys53, Arg70, Glu71 and Leu167 and the electrostatic interaction energies with residues Lys53 and Glu71, which surround the binding site (Figures 
A
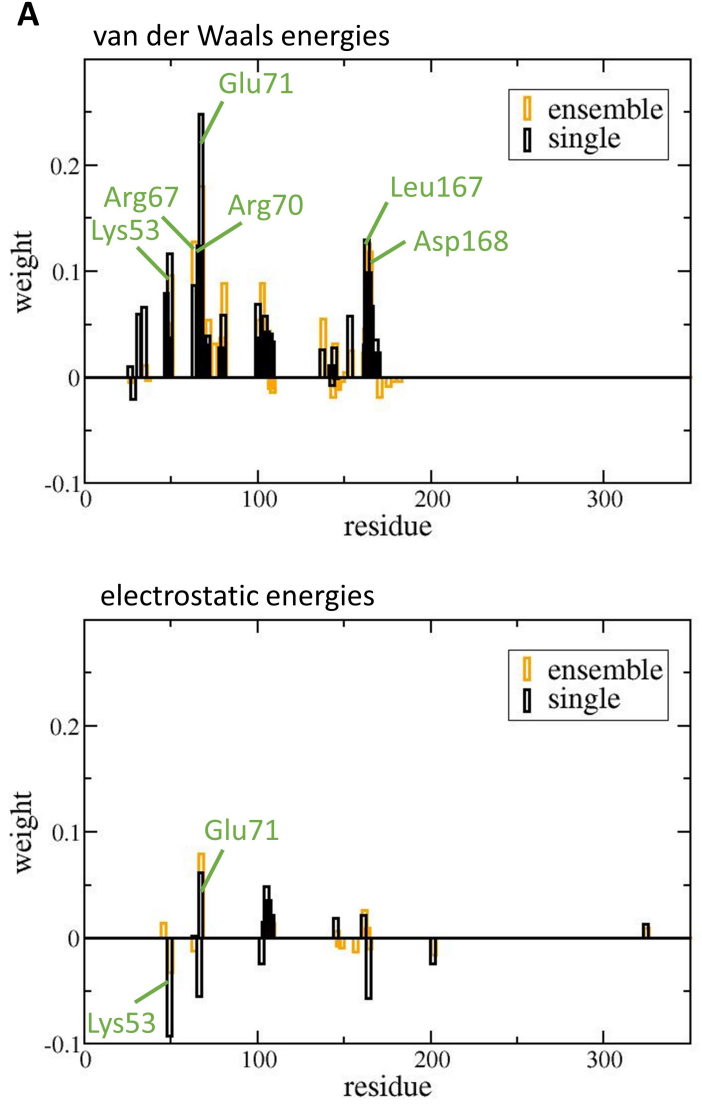

C

Ligand 2 (BIRB 796), $\mathrm{k}_{\text {off }}=8.310^{-6} \mathrm{~s}^{-1}\left(\right.$ low $\left.\mathrm{k}_{\text {off }}\right)$

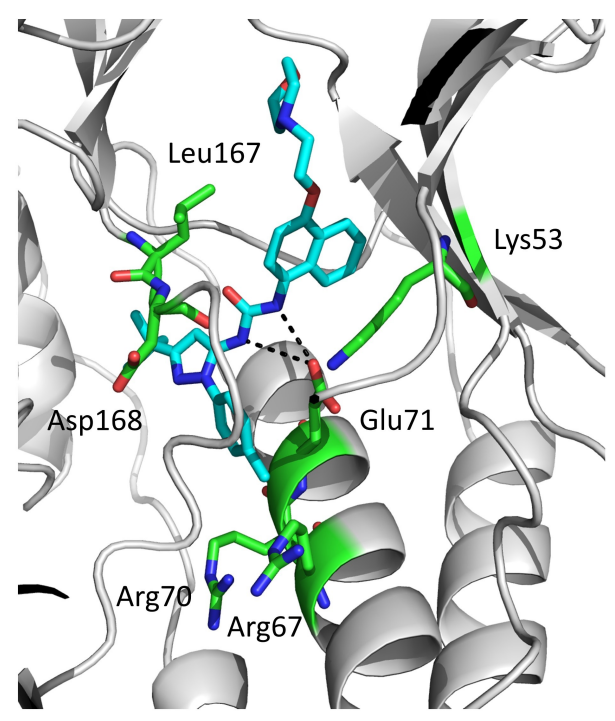

B
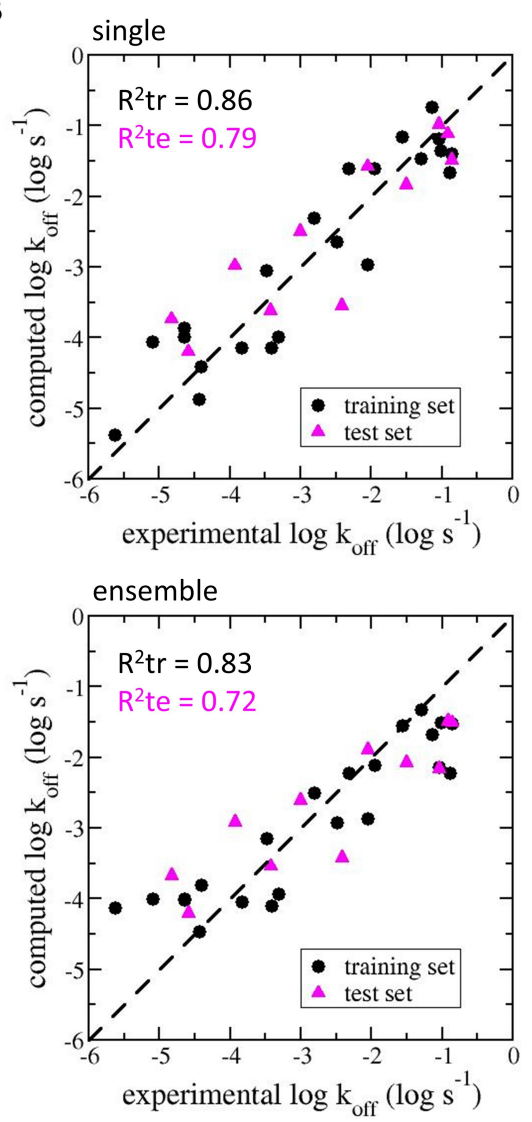

Ligand 25 (Imatinib), $\mathrm{k}_{\text {off }}=1.310^{-1} \mathrm{~s}^{-1}\left(\right.$ high $\left._{\text {off }}\right)$

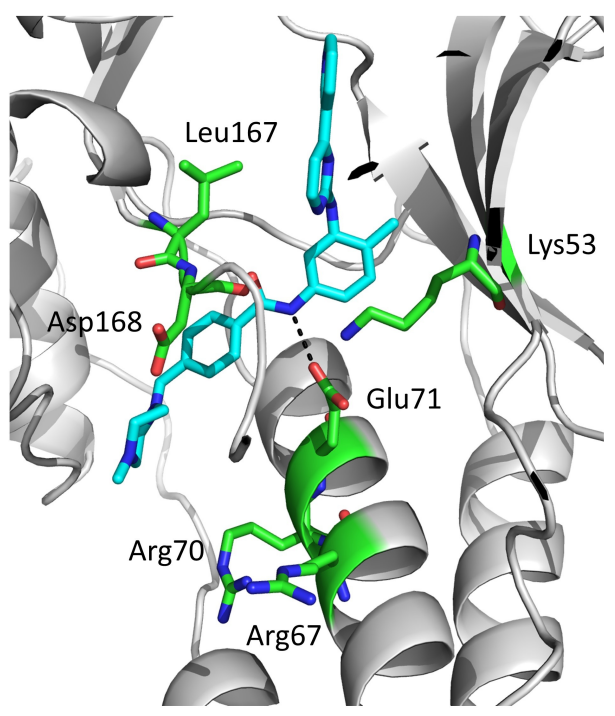


Figure 1: COMBINE analysis models to compute $\mathrm{k}_{\text {off }}$ values for p38 MAP kinase inhibitors. (A) Weights for different van der Waals and electrostatic interaction energies derived from partial least squares regression (PLS) using single structures (black) or ensemble docking (orange, bars displaced by 0.50 on the $\mathrm{x}$ axis to aid visualization). Results are shown for 2 or 1 latent variables for single structures or ensemble docking, respectively. Highlighted residues are shown in green in panel (C). (B) Plots of computed versus experimental log $\mathrm{k}_{\text {off }}$ values for the training and test sets (22 and 11 inhibitors, respectively) for PLS regression using single structures or ensemble docking. The straight line corresponds to $\mathrm{y}=\mathrm{x}$ (ideal case). (C) Comparison of binding modes and key interactions of a slow (ligand 2, BIRB 796, PDB 1KV2) and a fast dissociating inhibitor (ligand 25, Imatinib, PDB 3HEC). Protein backbone in gray, ligands and residues colored according to atom type, with carbon atoms in cyan and green, respectively. Hydrogen bonds are shown as black dotted lines.

$1 \mathrm{~A}$ and $1 \mathrm{C})$. The weight for the electrostatic interaction with Lys53 was negative, meaning that favorable interactions with this residue resulted in high $\mathrm{k}_{\text {off }}$ values. On the other hand, the weights for the electrostatic interaction with Glu71 and most van der Waals interactions were positive, indicating that favorable interactions with these residues result in low $\mathrm{k}_{o f f}$ values. Inhibitors with low $\mathrm{k}_{\text {off }}$ values usually make two hydrogen bonds with Glu71 and have two bulky hydrophobic groups, one making nonpolar interactions with Lys53 and the other making nonpolar interactions with the pocket formed by Arg70 and Glu71 (Figure 1C), in agreement with the interaction energies with highest weights identified in the model.

\subsection{COMBINE analysis using multiple structures from ensemble docking to represent one ligand-protein complex}

After making the reference model with one structure for each ligand, we made a COMBINE analysis model using a structural ensemble. A 1200-nanosecond MD simulation of p38 MAP kinase was performed to obtain different protein configurations. Protein configurations were collected every 80 nanoseconds for the last 800 nanoseconds of simulation, resulting in 10 protein configurations. Then, docking of the 33 p38 MAP kinase inhibitors to each of the 10 protein configurations was performed to obtain a total of 330 protein-ligand complexes. AutoDock Vina ${ }^{58}$ was used for ligand-protein docking, since it was able to reproduce the 
crystallographic poses of ligands 2 and 16 in redocking and cross-docking tests (ligand root mean squared deviation, RMSD, lower than $2 \AA$ in all cases, Table S3). For most ligands, ligand poses obtained from ensemble docking were similar (Figure S3) and had low RMSD from the ligand pose in the complex used in the COMBINE model with one structure to represent each complex. Ligands 21, 23, 24 and 26 are exceptions, as most ligand poses obtained from docking had high RMSD values from the ligand poses in the COMBINE model with one structure for each complex (Figure S4, Table S10 and discussion in section $4)$.

Ten energy-minimized structures from ensemble docking were used to represent each ligand-protein complex and obtain interaction energies. Using COMBINE analysis, 348 electrostatic and 348 van der Waals interaction energies for each of the 220 complexes (10 structures for each of the 22 p38 MAP kinase inhibitors) in the training set were calculated. Then the interaction energies that had a standard deviation greater than $0.25 \mathrm{kcal} / \mathrm{mol}$ were selected, resulting in 43 van der Waals interaction energies and 16 electrostatic interaction energies (Figure S2). Next, the weights of these 59 interaction energies for different numbers of latent variables were determined using PLS regression to correlate the interaction energies with the experimental $\log \mathrm{k}_{\text {off }}$ values (Figure $1 \mathrm{~A}$ ). Independent $\log \mathrm{k}_{\text {off }}$ values were computed for each structure describing one ligand-protein complex, and these values were later assembled in one computed $\mathrm{k}_{\text {off }}$ value for the complex using an exponential average (section 2.3). $\mathrm{R}^{2}, \mathrm{Q}^{2}$, AAEtr, AAEv, RMEtr and RMEv values were calculated using different numbers of latent variables (Tables 1 and S5). The model with one latent variable was selected, since it had the best compromise between high $\mathrm{Q}^{2}$ value $(0.70$ when the leave-one-out method was used for cross-validation) and low number of latent variables (Table S5). The AAEv and RMEv values were $0.68 \log \mathrm{s}^{-1}$ and $0.82 \log \mathrm{s}^{-1}$, respectively, for the leave-one-out method for cross-validation. Moreover, the $\mathrm{Q}^{2}, \mathrm{AAEv}$ and RMEv values were similar for the different cross-validation methods used (Table 1), showing that the model with one latent variable is consistent. The model with one latent variable presented a $R^{2} \operatorname{tr}$ of 0.83 , showing it could 
fit the data of the training set (Figure 1B, Table S5). The $\mathrm{R}^{2}$ te value for the test set of 11 inhibitors was 0.72 (Figure 1B, Table 1), showing this model had good predictive power.

The interaction energies with the highest weights were the van der Waals interaction energies of the inhibitors with residues Arg67, Glu71, Leu167 and Asp168 and the electrostatic interaction energies with residues Lys53 and Glu71 (Figures 1A and 1C). Some of the major contributions identified using COMBINE analysis and single structures, like electrostatic interactions with Lys53 and Glu71 and van der Waals interactions with Glu71 and Leu167, were also captured in the model with ensemble docking. Moreover, the use of structural ensembles helped to highlight the contributions of interactions with residues Arg67 and Asp168 in the DFG motif, which came closer to the binding site during MD simulations (Figure 2). The contributions from these two residues were high in the model using single structures, and became dominant in the model using an ensemble of structures.

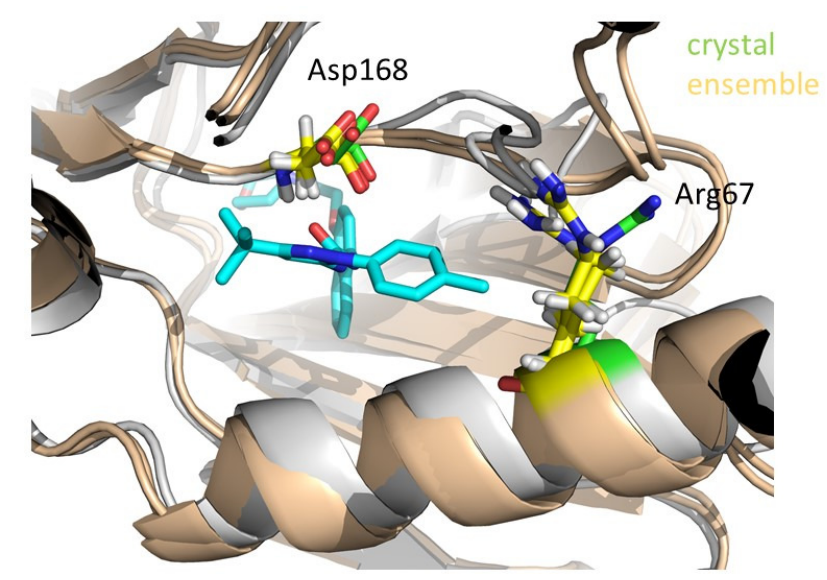

Figure 2: The use of ensemble docking to include protein and ligand flexibility in COMBINE analysis helped to highlight the contributions of interactions with residues Arg67 and Asp168. Arg67 and Asp168 side chains moved closer into the binding site during MD simulations. Ligand 2 (BIRB 796), Arg67 and Asp168 are shown in sticks. Protein backbone in gray (crystal structure, PDB 1KV2) or wheat (structure from MD simulation), ligand and residues colored according to atom type, with carbon atoms in cyan (ligand), green (residue in crystal structure) or yellow (residue in MD simulation).

Tests with COMBINE analysis were also performed using 20 instead of 10 structures to represent each protein-ligand complex, or using one structure, the one with the highest Vina 
score, to represent each protein-ligand complex. A higher number of interaction energies was selected when more structures were used (52, 59 and 68 for 1, 10 and 20 structures, respectively). For one structure, the model with two latent variables had the best compromise between high $\mathrm{Q}^{2}$ value (0.65 when the leave-one-out method was used for cross-validation) and low number of latent variables (Table S6). For 20 structures, the model with one latent variable had the best compromise between high $\mathrm{Q}^{2}$ value (0.65) and low number of latent variables (Table S7). The highest predictive power was achieved with the model with one structure, while the predictive power of models with multiple structures was similar $\left(\mathrm{R}^{2}\right.$ te values of $0.80,0.72$ and 0.71 for 1,10 and 20 structures, respectively). The maximum $\mathrm{R}^{2}$ te value achieved by the COMBINE analysis models with ensemble docking was 0.80, which is similar to the $\mathrm{R}^{2}$ te value achieved with the model which used single structures, 0.79 , indicating that the structural information to achieve predictive models using single crystal structures can be recovered in ensemble docking.

Comparisons between the different COMBINE analysis models obtained using a single crystal structure or structures from ensemble docking to represent one ligand-protein complex can help us to understand the weaknesses and strengths of each model. A similar $\mathrm{R}^{2} \operatorname{tr}$ value was obtained from COMBINE analysis using one or multiple structures (0.86 vs. 0.83, respectively; Tables S4 and S5), indicating that both models can basically make good fits for the training set. Both models could also reproduce the ranking for a small ligand series composed of ligands 13 (training set), 3 and 14 (test set), which differ by only one substitution (Figure 3). However, the overall $\mathrm{R}^{2}$ te value was higher for the model using one structure (0.79 and 0.72 for the models using one or multiple structures, respectively, Table 1), indicating that the group of interaction energies selected in the model with one structure had a higher predictive power. Possible reasons for the selection of interaction energies with lower predictive power in the model with multiple structures include worse signal to noise ratio, the lack of sampling of important protein configurations or poor ligand positions obtained from docking. The latter was the case for some ligands, as their RMSD 
value between docking and crystallographic positions was higher than $2 \AA$ (Figure S4 and discussion in section 4). For instance, considering the test set, ligands 5 and 16 had a high prediction error (difference between experimental and computed log $\mathrm{k}_{\text {off }}$ higher than $1 \log$ $\mathrm{s}^{-1}$ ) for the model using one structure. These ligands also had a high prediction error for the model using multiple structures, together with ligand 21, which had a poor prediction of ligand positions from docking.
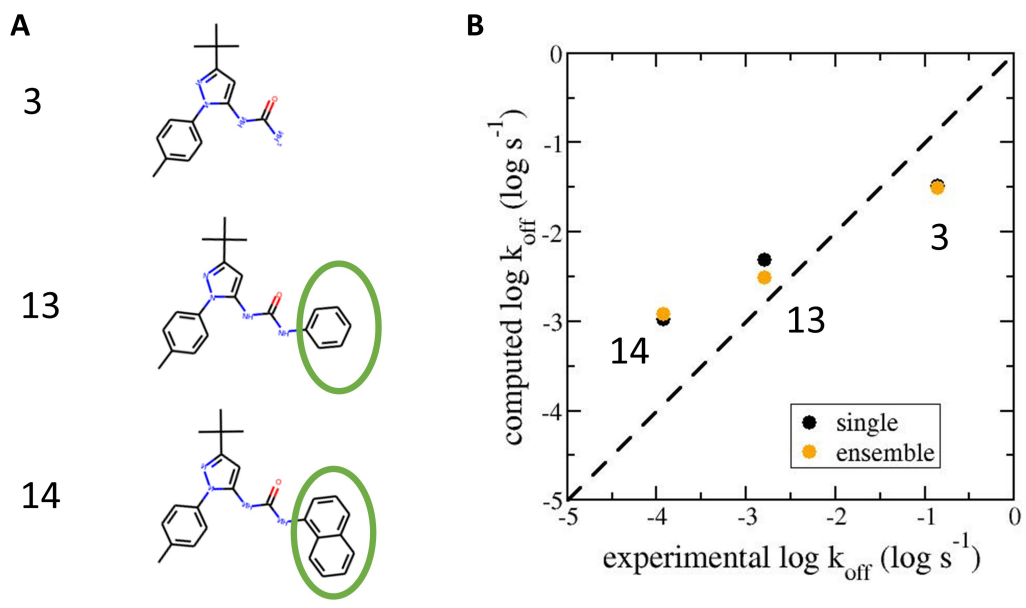

Figure 3: COMBINE analysis models to compute $\mathrm{k}_{\text {off }}$ values for $\mathrm{p} 38 \mathrm{MAP}$ kinase inhibitors can reproduce the ranking for a small series composed of ligands 13 (training set), 3 and 14 (test set). (A) Chemical structures of the ligands in the series. Green circles indicate the differences among the ligands. (B) Plot of computed versus experimental log $\mathrm{k}_{\text {off }}$ values for the ligands in the series. COMBINE analysis models were obtained using single structures (two latent variables) or ensemble docking (one latent variable). The straight line corresponds to $\mathrm{y}=\mathrm{x}$ (ideal case). For ligand $13, \mathrm{k}_{\text {off }}$ values were computed from training, while for ligands 3 and $14 \mathrm{k}_{\text {off }}$ values were computed from testing.

COMBINE analysis was also used to predict equilibrium dissociation constants $\left(\mathrm{K}_{d}\right)$ using a single crystal structure or structures from ensemble docking to represent each complex. The $\mathrm{R}^{2} \operatorname{tr}$ and $\mathrm{R}^{2}$ te values obtained for these models (tables $\mathrm{S} 8$ and $\mathrm{S} 9$ ) were lower than the ones obtained from COMBINE analysis to predict $\mathrm{k}_{\text {off }}$ values, showing that model training was less successful and the predictive power was lower for models to predict $\mathrm{K}_{d}$. The COMBINE analysis, as implemented in this work, considers only interaction energies between the ligand and the protein in the bound state. However, predictions for $\mathrm{k}_{\text {off }}$ and $\mathrm{K}_{d}$ values also depend 
on the energies of the transition and unbound states, respectively. The transition state is structurally not far from the bound state and can have interactions in common with it, while the bound state is not structurally related to the unbound state. The structural similarity between transition and bound states may explain why good predictions were obtained for $\mathrm{k}_{\text {off }}$ values, but not for $\mathrm{K}_{d}$ values.

\section{Discussion}

The present study is the second to apply COMBINE analysis to predict experimental $\mathrm{k}_{\text {off }}$ values. In the first study, ${ }^{9}$ two independent COMBINE analyses were performed to predict $\mathrm{k}_{\text {off }}$ values using a training set of 53 inhibitors of the heat shock protein 90 (HSP90) and 33 inhibitors of HIV-1 protease, resulting in models with $\mathrm{Q}^{2}$-LOO values of 0.69 and 0.70 , respectively. The present study achieved a higher $\mathrm{Q}^{2}$-LOO value, 0.75 , despite the fact that less crystallographic data was available for the ligand-protein complexes $(37 / 66,12 / 33$ and 6/33 complexes had crystal structures available for HSP90, HIV-1 protease and p38 MAP kinase, respectively), resulting in greater uncertainty in the modeling. A $\mathrm{Q}^{2}$-LOO value similar to the previous study was achieved for the model with multiple structures.

Previous studies used MD simulations or regression methods to predict $\mathrm{k}_{\text {off }}$ values for $\mathrm{p} 38$ MAP kinase inhibitors (Table S11). A method combining steered molecular dynamics (SMD) and computation of free energies of dissociation obtained $\mathrm{R}^{2}$ te of 0.88 for a dataset comprised of eight inhibitors. ${ }^{72}$ In another study, a model obtained using PLS regression, a training set of 14 inhibitors, a test set of 6 inhibitors and protein-inhibitor interaction fingerprints (IFPs) from simulations of inhibitor dissociation had $R^{2}$ te of 0.56 and $R^{2} \operatorname{tr}$ of $0.72 .{ }^{73}$ Negative binding energy integrals obtained from ligand dissociation using local-scaled MD achieved $\mathrm{R}^{2}$ te of 0.64 in the prediction of $\mathrm{k}_{\text {off }}$ values for 41 complexes with different kinases, including

12 complexes with p38 MAP kinase. ${ }^{74}$ Amongst regression methods, Volsurf, a method which uses descriptors from the structures of inhibitors only, resulted in a model with $\mathrm{R}^{2}$ te of 0.82 
and $\mathrm{R}^{2} \operatorname{tr}$ of 0.82 for a training set of 18 inhibitors and a test set of 10 inhibitors. ${ }^{75}$ A model obtained using random forest, ligand-protein interactions and information about the protein structure as descriptors achieved $\mathrm{R}^{2}$ te of 0.43 for a test set of 28 complexes with p38 MAP kinase. ${ }^{76}$ The study presented here had a $\mathrm{R}^{2} \operatorname{tr}$ higher than the method with the highest $\mathrm{R}^{2} \operatorname{tr}$ value, Volsurf, and $\mathrm{R}^{2}$ te value lower than the method with the highest predictive power, the method based on SMD. On one hand, the SMD method includes more details about the ligand-protein interactions and the unbinding process. On the other hand, it was tested using only 8 inhibitors. Despite only inhibitor structures being considered, Volsurf had a good fit for the training set. However, regression methods like Volsurf are usually not able to directly identify important protein residues acting in the modulation of inhibitor-protein binding kinetics.

Previous computational and experimental studies also identified inhibitor-protein interactions and inhibitor features that contribute to lower $\mathrm{k}_{\text {off }}$ values. Van der Waals interactions and hydrogen bonds of inhibitors with Glu71 were identified as important factors for lowering $\mathrm{k}_{\text {off }}$ values in SKR studies. ${ }^{24,26}$ These features were also observed in the COMBINE analyses presented here. Weaker electrostatic interactions contributing to lower $\mathrm{k}_{\text {off }}$ values is a trend which was identified in a study using IFPs from simulations of inhibitor dissociation. ${ }^{73}$ Here, this trend is also observed, as there is a negative weight for the electrostatic interaction between the inhibitors and Lys53, indicating that weaker electrostatic interactions with Lys53 contribute to lower $\mathrm{k}_{\text {off }}$ values. In the study using IFPs,${ }^{73}$ stronger van der Waals interactions were found to contribute to lower $\mathrm{k}_{\text {off }}$ values, and interactions with charged residues, such as Arg67 and Arg70, were involved in the modulation of $\mathrm{k}_{\text {off }}$ values. Interactions with these residues were also identified as modulators of $\mathrm{k}_{\text {off }}$ values in the COMBINE analyses presented here. Other residues identified by COMBINE analysis, such as Lys53, Glu71 and Leu167, were not identified by the study using IFPs, which may be related to differences in the training set used or in the methods, as the IFPs were obtained from simulations of inhibitor dissociation, while the interaction energies from COMBINE 
analysis were obtained from ligand-protein complexes in the bound state. Moreover, the contribution of larger molecular volumes and stronger van der Waals interactions to lower $\mathrm{k}_{\text {off }}$ values, found using Volsurf ${ }^{75}$ and IFPs, ${ }^{73}$ agrees with the overall results obtained in COMBINE analyses, since most interaction energies with high weights are van der Waals interactions.

Computational predictions in this work are supported by data for mutations generating drug resistance in EGFR and $\mathrm{Abl}$ kinases. In the COMBINE analysis using one structure, interactions with residues Lys53, Arg70, Glu71 and Leu167 were identified as important for long residence times. Additionally, in the COMBINE analysis using an ensemble of structures, interactions with residues Arg67 and Asp168 were highlighted as important for long residence times. Mutations in positions $282^{77,78}$ and $285^{78}$ of $\mathrm{Abl}$ kinase (equivalent to positions 67 and 70 in p38 MAP kinase, respectively, Figure S5a) and in position 759 of EGFR ${ }^{79}$ (equivalent to position 71 in p38 MAP kinase, Figure S5b) are associated with drug resistance, supporting the importance of residues Arg67, Arg70 and Glu71 in inhibitor binding.

As pointed out in section 3.2 , the $\mathrm{R}^{2}$ te value was higher for the model using one structure than for the model using multiple structures (0.79 and 0.72 for the models using one or multiple structures, respectively, Table 1), indicating that the group of interaction energies selected in the model with one structure had a higher predictive power. One of the possible reasons for this is poor binding modes for ligands obtained from ensemble docking (Figure S4). Docking using a protein ensemble led to improved binding modes ${ }^{23}$ and a higher area under the receiver operating characteristic (ROC) curve (AUC) ${ }^{16}$ in previous studies. Here, there were discrepancies between the reference binding modes (the binding modes in the model using one structure) and the binding modes from ensemble docking for ligands 23, 26 (training set), 21 and 24 (test set), which had from 8/10 up to 10/10 binding modes with RMSD higher than $5 \AA$ from the ligand in the reference structure (Figure S4, Table S10). Additionally, these ligands had low prediction errors in the COMBINE analysis model using 
one crystal structure (0.06 to $\left.0.38 \log \mathrm{s}^{-1}\right)$, but average $\left(0.55\right.$ to $0.58 \log \mathrm{s}^{-1}$ for ligands 24 and 26) to high (1.11 to $1.12 \log \mathrm{s}^{-1}$ for ligands 21 and 23) errors in the COMBINE analysis model using multiple structures.

Visual inspection of the crystal structures used to obtain the reference binding modes for ligands 21, 23 and 24 showed that a significant structural rearrangement happens for residues Lys53 and Glu71. Moreover, visual inspection of the crystal structure used to obtain the reference binding mode for ligand 26 shows a Val in position 84, while this position is occupied by a bulkier residue, Ile, in p38 MAP kinase. Docking was performed treating residues Lys53 and Glu71 (ligands 21, 23 and 24) or residue Ile 84 (ligand 26) as flexible, but this did not improve significantly the binding modes (Table S10). As the reference binding modes for these ligands are complexes with other kinases, it is possible that these ligands could have different binding modes with p38 MAP kinase, or that other residues of p38 MAP kinase, not explored in flexible docking, may need to reorganize for ligand binding.

Another possible reason for the higher predictive power of the model using single structures, compared to the model using an ensemble to represent each ligand-protein complex, is the diversity of structures. Regarding the disordered region after the DFG motif (residues 170 to 184 in PDB 1KV2), the six crystal structures used in the model with single structures presented a higher structural diversity than the 10 protein structures selected for ensemble docking (Figure S6c). As noted before, the region after the DFG motif was missing in the six crystal structures, and structural diversity came from modeling with Modeller (Section 2.4). The sampling of structures for the ensemble-based model could be improved by the use of enhanced sampling MD simulation techniques but further work would be necessary to investigate whether this results in improved predictive ability.

The current COMBINE analysis model presented here deals with one of the approximations of previous models, the treatment of protein flexibility. However, there are other approximations in the present COMBINE analysis model which could be improved in future work. One of them is the lack of consideration of the transition state ensemble. For 
instance, inhibitors could have similar bound states but different transition state ensembles, what would lead to different experimental $\mathrm{k}_{\text {off }}$ values. Describing such an ensemble requires knowledge of the dissociation path, which could make the preparation for COMBINE analysis computationally expensive. Moreover, the description of such an ensemble can be challenging if many dissociation pathways are available. This is the case, for instance, for the T4 lysozyme L99A mutant, for which eight dissociation pathways have been identified. ${ }^{4}$ So far, three dissociation pathways were identified for inhibitors of p38 MAP kinase. ${ }^{74,80,81}$

Another approximation of the present COMBINE analysis model is the lack of consideration of protein conformational changes during inhibitor dissociation. Bulkier inhibitors may require larger conformational changes and, therefore, show a higher energy penalty for leaving the protein binding site and reaching the solvent, leading to lower $\mathrm{k}_{\text {off }}$ values. A previous study $^{81}$ sampled dissociation paths for type I and type II inhibitors of p38 MAP kinase, and identified by umbrella sampling that the dissociation of type II inhibitors presented larger energy barriers due to the larger protein motions required for inhibitor dissociation, which explained the lower $\mathrm{k}_{\text {off }}$ values for these inhibitors. The dataset of the present study contained type II inhibitors only, which probably minimized the problems arising from the lack of consideration of protein conformational changes during dissociation. However, such changes may be important for proteins with buried binding sites or large conformation changes for ligand unbinding, such as HIV protease.

One of the motivations of performing COMBINE analysis to predict $\mathrm{k}_{\text {off }}$ values or other biological activity is the speed of the parametrization and application of the method, especially for large datasets with tens or hundreds of inhibitors. One of the advantages of using one structure over multiple structures in COMBINE analysis is the lower computational cost, as usually only a single crystal structure and no simulations, just energy minimizations, are required when one structure is used to represent the ligand-protein complex. For the model with multiple structures obtained here, the computational bottleneck of the method was running one MD simulation of 1200 nanoseconds for a ligand-protein complex to obtain the 
configurational ensemble. This simulation length allowed the collection of more diverse protein structures (RMSD values and protein structures in Figure S6). High root mean squared fluctuations and structural variation close to the DFG motif (Figure S6) suggest flexibility is important for ligand binding to p38 MAP kinase. While docking with Vina took seconds for each ligand-protein pair, running the MD simulation took approximately 6 days using 1 GPU (NVIDIA Tesla P40). Therefore, inclusion of protein and ligand flexibility in COMBINE analysis can be achieved with modest increases in computational time. Moreover, the increase in computational time can be reduced by running a shorter MD simulation, or obtaining a configurational ensemble from other sources, like NMR data, crystal structures or computational methods such as the iterative Anisotropic Network Model (iterANM). ${ }^{23}$

Despite the increase in computational time compared to the model with a single structure, COMBINE analysis using multiple structures for one ligand-protein complex can be useful in cases where flexibility cannot be neglected. Here, a region in p38 MAP kinase close to the binding site was not resolved in all crystal structures of ligand-protein complexes, suggesting this region was highly flexible. The use of COMBINE analysis with multiple structures helped to reveal more residues involved in the modulation of $\mathrm{k}_{\text {off }}$ values. COMBINE analysis with multiple structures can also be applied in cases where the ligand has multiple binding modes, or in cases where the protein shows multiple conformations or rotamers for residues, especially in the binding site.

\section{Conclusions}

We propose a method to incorporate protein and ligand flexibility in COMBINE analysis using arithmetic or exponential averaging of the predicted $\mathrm{k}_{\text {off }}$ values from multiple structures describing one ligand-protein complex. Here, such structures were obtained from docking the ligand to a protein ensemble from MD simulations, but protein ensembles can also be obtained from multiple crystal structures or from NMR. We obtained models for $\mathrm{k}_{\text {off }}$ values 
for inhibitors of p38 MAP kinase with good predictive power $\left(\mathrm{R}^{2} \mathrm{te}=0.79, \mathrm{R}^{2} \operatorname{tr}=0.86\right.$ and $\mathrm{R}^{2}$ te $=0.72, \mathrm{R}^{2} \operatorname{tr}=0.83$ for one and multiple structures, respectively) and identified key ligand-protein interactions that contribute to variance in binding kinetics. COMBINE analysis identified known important residues, such as Arg70 and Glu71, and also additional relevant residues, such as Lys53 and Leu167. Moreover, the incorporation of protein-ligand flexibility helped to highlight more residues connected to long residence times, such as Arg67 and Asp168. These specific interaction energies provide insights into the mechanisms of action of slow and fast dissociating inhibitors.

\section{Data and Software Availability}

The software to apply ensemble COMBINE analysis is available, with an example (using the structures from ensemble docking describe here), at https://github.com/HITS-MCM/ensembleCOMBINE. The python script for ligand superimposition is available at https://github.com/HITS-MCM/LigSuperposition. The input files and the files with coordinates and topologies of the ligand-protein complexes which were used to obtain the models using single structures or an ensemble of structures to represent each ligand-protein complex can be obtained at: https://doi.org/10.5281/zenodo.4597725.

\section{Acknowledgement}

ANA thanks Dr. Gaurav Ganotra for initial help and assistance with COMBINE analysis. The authors thank Dr. Alvaro Cortes Cabrera for providing the code for COMBINE analysis, Dr. Daria Kokh for help with the script for ligand superimposition, and Dr. Daria Kokh and Christina Athanasiou for critical review of the manuscript. This work was supported by a Capes-Humboldt postdoctoral scholarship to ANA (Capes process number 88881.162167/2017-01), funds from the Cluster of Excellence CellNetworks (DFG, EXC81) to ANA and the Klaus Tschira Foundation. 


\section{Supporting Information Available}

Supporting Information is available free of charge on the ACS Publications website. The supporting information (PDF file) contains: chemical structures of the 33 inhibitors of p38 MAP kinase used for COMBINE analysis (Figure S1); interaction energies between p38 MAP kinase amino acid residues and inhibitors (Figure S2); binding modes obtained from ensemble docking for ligands 2 and 23 (Figure S3); histograms of root mean squared deviations (RMSD) between the ligand position in the crystal structure and the ligand position in the 10 complexes obtained from ensemble docking (Figure S4); alignment of p38 MAP kinase with the human Abl kinase or with the human EGFR kinase (Figure S5); structural variation of proteins in the models using single structures or an ensemble of structures to represent each ligand-protein complex (Figure S6); list of the SMILES strings for the p38 MAP kinase inhibitors (Table S1); list of the experimental crystal structures and $\mathrm{k}_{\text {off }}$ values (in $\mathrm{s}^{-1}$ ) for the p38 MAP kinase inhibitors (Table S2); root mean squared deviations (RMSD) between the ligand position in the crystal structure and the ligand position obtained from redocking or cross-docking to the p38 MAP kinase structures in PDBs 1KV2 or 3HV6 using Vina (Table S3); summary of the models derived for different numbers of latent variables (LVs) for COMBINE analysis for log $\mathrm{k}_{\text {off }}$ of p38 MAP kinase inhibitors using crystal structures (one structure per ligand, Table S4) or structures from ensemble docking (10 structures per ligand, Table S5; 1 structure per ligand, Table S6; 20 structures per ligand, Table S7); summary of the models derived for different numbers of latent variables (LVs) for COMBINE analysis for $\log \mathrm{K}_{d}$ of p38 MAP kinase inhibitors using crystal structures (one structure per ligand, Table S8) or structures from ensemble docking (10 structures per ligand, Table S9); number of binding modes from ensemble docking with root mean squared deviation (RMSD) from the binding mode in the reference structure higher than $5 \AA$ (Table S10); statistical measures of previous studies which predicted $\mathrm{k}_{\text {off }}$ values for inhibitors of p38 MAP kinase (Table S11); section with equations for coefficient of determination, average absolute error and root mean squared error (Section S1); section with description and validation of the 
custom script used for ligand superimposition (Section S2).

\section{References}

(1) Copeland, R. A. The drug-target residence time model: a 10-year retrospective. Nat. Rev. Drug Discov. 2016, 15, 87-95.

(2) Schuetz, D. A. et al. Kinetics for Drug Discovery: an industry-driven effort to target drug residence time. Drug Discov. Today 2017, 22, 896-911.

(3) Bernetti, M.; Cavalli, A.; Mollica, L. Protein-ligand (un)binding kinetics as a new paradigm for drug discovery at the crossroad between experiments and modelling. Med. Chem. Commun. 2017, 8, 534-550.

(4) Nunes-Alves, A.; Kokh, D. B.; Wade, R. C. Recent progress in molecular simulation methods for drug binding kinetics. Curr. Opin. Struct. Biol. 2020, 64, 126-133.

(5) Kokh, D. B.; Amaral, M.; Bomke, J.; Grädler, U.; Musil, D.; Buchstaller, H.-P.; Dreyer, M. K.; Frech, M.; Lowinski, M.; Vallee, F.; Bianciotto, M.; Rak, A.; Wade, R. C. Estimation of Drug-Target Residence Times by $\tau$-Random Acceleration Molecular Dynamics Simulations. J. Chem. Theory Comput. 2018, 14, 3859-3869.

(6) Mollica, L.; Decherchi, S.; Zia, S. R.; Gaspari, R.; Cavalli, A.; Rocchia, W. Kinetics of protein-ligand unbinding via smoothed potential molecular dynamics simulations. Sci. Rep. 2015, 5, 11539.

(7) Huber, G. A.; Kim, S. Weighted-ensemble Brownian dynamics simulations for protein association reactions. Biophys. J. 1996, 70, 97-110.

(8) Zuckerman, D. M.; Chong, L. T. Weighted Ensemble Simulation: Review of Methodology, Applications, and Software. Annu. Rev. Biophys. 2017, 46, 43-57. 
(9) Ganotra, G. K.; Wade, R. C. Prediction of Drug-Target Binding Kinetics by Comparative Binding Energy Analysis. ACS Med. Chem. Lett. 2018, 9, 1134-1139.

(10) Qu, S.; Huang, S.; Pan, X.; Yang, L.; Mei, H. Constructing Interconsistent, Reasonable, and Predictive Models for Both the Kinetic and Thermodynamic Properties of HIV-1 Protease Inhibitors. J. Chem. Inf. Model. 2016, 56, 2061-2068.

(11) Ortiz, A. R.; Pisabarro, M. T.; Gago, F.; Wade, R. C. Prediction of Drug Binding Affinities by Comparative Binding Energy Analysis. J. Med. Chem. 1995, 38, 26812691.

(12) Peters, M. B.; Merz, K. M. Semiempirical Comparative Binding Energy Analysis (SECOMBINE) of a Series of Trypsin Inhibitors. J. Chem. Theory Comput. 2006, 2, 383399.

(13) Liu, S.; Fu, R.; Cheng, X.; Chen, S.-P.; Zhou, L.-H. Exploring the binding of BACE-1 inhibitors using comparative binding energy analysis (COMBINE). BMC Struct. Biol. 2012, 12, 21.

(14) Wang, T.; Wade, R. C. Comparative Binding Energy (COMBINE) Analysis of OppAPeptide Complexes to Relate Structure to Binding Thermodynamics. J. Med. Chem. $2002,45,4828-4837$.

(15) Tomić, S.; Bertoša, B.; Wang, T.; Wade, R. C. COMBINE analysis of the specificity of binding of Ras proteins to their effectors. Proteins 2007, 67, 435-447.

(16) Cleves, A. E.; Jain, A. N. Structure- and Ligand-Based Virtual Screening on DUDE+: Performance Dependence on Approximations to the Binding Pocket. J. Chem. Inf. Model. 2020, 60, 4296-4310.

(17) Arantes, G. M. Flexibility and inhibitor binding in Cdc25 phosphatases. Proteins 2010, 78, 3017-3032. 
(18) Nunes-Alves, A.; Arantes, G. M. Ligand-receptor affinities computed by an adapted linear interaction model for continuum electrostatics and by protein conformational averaging. J. Chem. Inf. Model. 2014, 54, 2309-2319.

(19) Bhattarai, A.; Wang, J.; Miao, Y. Retrospective ensemble docking of allosteric modulators in an adenosine G-protein-coupled receptor. Biochim. Biophys. Acta Gen. Subj. 2020, 1864, 129615.

(20) Olubiyi, O. O.; Olagunju, M.; Keutmann, M.; Loschwitz, J.; Strodel, B. High Throughput Virtual Screening to Discover Inhibitors of the Main Protease of the Coronavirus SARS-CoV-2. Molecules 2020, 25, 3193.

(21) Noé, F.; Olsson, S.; Köhler, J.; Wu, H. Boltzmann generators: Sampling equilibrium states of many-body systems with deep learning. Science 2019, 365 .

(22) Degiacomi, M. T. Coupling Molecular Dynamics and Deep Learning to Mine Protein Conformational Space. Structure 2019, 27, 1034-1040.e3.

(23) Wang, A.; Zhang, Y.; Chu, H.; Liao, C.; Zhang, Z.; Li, G. Higher Accuracy Achieved for Protein-Ligand Binding Pose Prediction by Elastic Network Model-Based Ensemble Docking. J. Chem. Inf. Model. 2020, 60, 2939-2950.

(24) Pargellis, C.; Tong, L.; Churchill, L.; Cirillo, P. F.; Gilmore, T.; Graham, A. G.; Grob, P. M.; Hickey, E. R.; Moss, N.; Pav, S.; Regan, J. Inhibition of p38 MAP kinase by utilizing a novel allosteric binding site. Nat. Struct. Mol. Biol. 2002, 9, 268-272.

(25) Wu, P.; Nielsen, T. E.; Clausen, M. H. FDA-approved small-molecule kinase inhibitors. Trends Pharmacol. Sci. 2015, 36, 422-439.

(26) Regan, J.; Pargellis, C. A.; Cirillo, P. F.; Gilmore, T.; Hickey, E. R.; Peet, G. W.; Proto, A.; Swinamer, A.; Moss, N. The kinetics of binding to p38 MAP kinase by analogues of BIRB 796. Bioorg. Med. Chem. Lett. 2003, 13, 3101-3104. 
(27) Millan, D. S. et al. Design and Synthesis of Inhaled p38 Inhibitors for the Treatment of Chronic Obstructive Pulmonary Disease. J. Med. Chem. 2011, 54, 7797-7814.

(28) Redhead, M.; Satchell, R.; Morkūnaitè, V.; Swift, D.; Petrauskas, V.; Golding, E.; Onions, S.; Matulis, D.; Unitt, J. A combinatorial biophysical approach; FTSA and SPR for identifying small molecule ligands and PAINs. Anal. Biochem. 2015, 479, $63-73$.

(29) Georgi, V.; Schiele, F.; Berger, B.-T.; Steffen, A.; Marin Zapata, P. A.; Briem, H.; Menz, S.; Preusse, C.; Vasta, J. D.; Robers, M. B.; Brands, M.; Knapp, S.; FernándezMontalván, A. Binding Kinetics Survey of the Drugged Kinome. J. Am. Chem. Soc. 2018, 140, 15774-15782.

(30) Gil-Redondo, R.; Klett, J.; Gago, F.; Morreale, A. gCOMBINE: A graphical user interface to perform structure-based comparative binding energy (COMBINE) analysis on a set of ligand-receptor complexes. Proteins 2010, 78, 162-172.

(31) Maier, J. A.; Martinez, C.; Kasavajhala, K.; Wickstrom, L.; Hauser, K. E.; Simmerling, C. ff14SB: Improving the Accuracy of Protein Side Chain and Backbone Parameters from ff99SB. J. Chem. Theory Comput. 2015, 11, 3696-3713.

(32) Rännar, S.; Lindgren, F.; Geladi, P.; Wold, S. A PLS kernel algorithm for data sets with many variables and fewer objects. Part 1: Theory and algorithm. J. Chemometrics $\mathbf{1 9 9 4 , ~ 8 , ~ 1 1 1 - 1 2 5 . ~}$

(33) Minh, D. D. L. Implicit ligand theory: rigorous binding free energies and thermodynamic expectations from molecular docking. J. Chem. Phys. 2012, 137, 104106.

(34) Klüter, S.; Grütter, C.; Naqvi, T.; Rabiller, M.; Simard, J. R.; Pawar, V.; Getlik, M.; Rauh, D. Displacement Assay for the Detection of Stabilizers of Inactive Kinase Conformations. J. Med. Chem. 2010, 53, 357-367. 
(35) Namboodiri, H. V.; Bukhtiyarova, M.; Ramcharan, J.; Karpusas, M.; Lee, Y.; Springman, E. B. Analysis of Imatinib and Sorafenib Binding to p38 $\alpha$ Compared with c-Abl and b-Raf Provides Structural Insights for Understanding the Selectivity of Inhibitors Targeting the DFG-Out Form of Protein Kinases. Biochemistry 2010, 49, 3611-3618.

(36) Šali, A.; Blundell, T. L. Comparative Protein Modelling by Satisfaction of Spatial Restraints. J. Mol. Biol. 1993, 234, 779-815.

(37) Gill, A. L. et al. Identification of Novel p38 $\alpha$ MAP Kinase Inhibitors Using FragmentBased Lead Generation. J. Med. Chem. 2005, 48, 414-426.

(38) Dolinsky, T. J.; Nielsen, J. E.; McCammon, J. A.; Baker, N. A. PDB2PQR: an automated pipeline for the setup of Poisson-Boltzmann electrostatics calculations. Nucleic Acids Res. 2004, 32, W665-W667.

(39) Unni, S.; Huang, Y.; Hanson, R. M.; Tobias, M.; Krishnan, S.; Li, W. W.; Nielsen, J. E.; Baker, N. A. Web servers and services for electrostatics calculations with APBS and PDB2PQR. J. Comput. Chem. 2011, 32, 1488-1491.

(40) O’Boyle, N. M.; Banck, M.; James, C. A.; Morley, C.; Vandermeersch, T.; Hutchison, G. R. Open Babel: an open chemical toolbox. J. Cheminform. 2011, 3, 33.

(41) van Linden, O. P. J.; Kooistra, A. J.; Leurs, R.; de Esch, I. J. P.; de Graaf, C. KLIFS: A Knowledge-Based Structural Database To Navigate Kinase-Ligand Interaction Space. J. Med. Chem. 2014, 57, 249-277.

(42) Kooistra, A. J.; Kanev, G. K.; van Linden, O. P.; Leurs, R.; de Esch, I. J.; de Graaf, C. KLIFS: a structural kinase-ligand interaction database. Nucleic Acids Res. 2015, 44 , D365-D371.

(43) Karoulia, Z.; Wu, Y.; Ahmed, T. A.; Xin, Q.; Bollard, J.; Krepler, C.; Wu, X.; Zhang, C.; Bollag, G.; Herlyn, M.; Fagin, J. A.; Lujambio, A.; Gavathiotis, E.; 
Poulikakos, P. I. An Integrated Model of RAF Inhibitor Action Predicts Inhibitor Activity against Oncogenic BRAF Signaling. Cancer Cell 2016, 30, 485-498.

(44) Schroeder, G. M. et al. Discovery of N-(4-(2-Amino-3-chloropyridin-4-yloxy)-3fluorophenyl)-4-ethoxy-1-(4-fluorophenyl)-2-oxo-1,2-dihydropyridine-3-carboxamide (BMS-777607), a Selective and Orally Efficacious Inhibitor of the Met Kinase Superfamily. J. Med. Chem. 2009, 52, 1251-1254.

(45) Chan, W. W. et al. Conformational control inhibition of the BCR-ABL1 tyrosine kinase, including the gatekeeper T315I mutant, by the switch-control inhibitor DCC-2036. Cancer Cell 2011, 19, 556-568.

(46) Qian, F. et al. Inhibition of Tumor Cell Growth, Invasion, and Metastasis by EXEL2880 (XL880, GSK1363089), a Novel Inhibitor of HGF and VEGF Receptor Tyrosine Kinases. Cancer Res. 2009, 69, 8009-8016.

(47) Heinzlmeir, S.; Kudlinzki, D.; Sreeramulu, S.; Klaeger, S.; Gande, S. L.; Linhard, V.; Wilhelm, M.; Qiao, H.; Helm, D.; Ruprecht, B.; Saxena, K.; Médard, G.; Schwalbe, H.; Kuster, B. Chemical Proteomics and Structural Biology Define EPHA2 Inhibition by Clinical Kinase Drugs. ACS Chem. Biol. 2016, 11, 3400-3411.

(48) Tröster, A.; Heinzlmeir, S.; Berger, B.-T.; Gande, S. L.; Saxena, K.; Sreeramulu, S.; Linhard, V.; Nasiri, A. H.; Bolte, M.; Müller, S.; Kuster, B.; Médard, G.; Kudlinzki, D.; Schwalbe, H. NVP-BHG712: Effects of Regioisomers on the Affinity and Selectivity toward the EPHrin Family. ChemMedChem 2018, 13, 1629-1633.

(49) Garner, A. P. et al. Ponatinib Inhibits Polyclonal Drug-Resistant KIT Oncoproteins and Shows Therapeutic Potential in Heavily Pretreated Gastrointestinal Stromal Tumor (GIST) Patients. Clin. Cancer Res. 2014, 20, 5745-5755.

(50) Smith, C. C. et al. Characterizing and Overriding the Structural Mechanism of the 
Quizartinib-Resistant FLT3 "Gatekeeper” F691L Mutation with PLX3397. Cancer Discov. 2015, 5, 668-679.

(51) McTigue, M.; Murray, B. W.; Chen, J. H.; Deng, Y.-L.; Solowiej, J.; Kania, R. S. Molecular conformations, interactions, and properties associated with drug efficiency and clinical performance among VEGFR TK inhibitors. Proc. Natl. Acad. Sci. U. S. A. 2012, 109, 18281-18289.

(52) RDKit: Open-Source Cheminformatics and Machine Learning, http://rdkit.org/.

(53) Michaud-Agrawal, N.; Denning, E. J.; Woolf, T. B.; Beckstein, O. MDAnalysis: a toolkit for the analysis of molecular dynamics simulations. J. Comput. Chem. 2011, 32, 2319-2327.

(54) Gowers, R. J.; Linke, M.; Barnoud, J.; Reddy, T. J. E.; Melo, M. N.; Seyler, S. L.; Domański, J.; Dotson, D. L.; Buchoux, S.; Kenney, I. M.; Beckstein, O. MDAnalysis: A Python Package for the Rapid Analysis of Molecular Dynamics Simulations. Proceedings of the 15th Python in Science Conference. 2016; pp 98-105.

(55) Velázquez-Libera, J. L.; Durán-Verdugo, F.; Valdés-Jiménez, A.; Núñez-Vivanco, G.; Caballero, J. LigRMSD: a web server for automatic structure matching and RMSD calculations among identical and similar compounds in protein-ligand docking. Bioinformatics 2020, 36, 2912-2914.

(56) Schaftenaar, G.; Noordik, J. H. Molden: a pre-- and post-processing program for molecular and electronic structures. J. Comput.-Aided Mol. Des. 2000, 14, 123-134.

(57) Case, D. A. et al. AMBER 2016, University of California, San Francisco. 2016.

(58) Trott, O.; Olson, A. J. AutoDock Vina: improving the speed and accuracy of docking with a new scoring function, efficient optimization, and multithreading. J. Comput. Chem. 2010, 31, 455-461. 
(59) Wang, J.; Wolf, R. M.; Caldwell, J. W.; Kollman, P. A.; Case, D. A. Development and testing of a general amber force field. J. Comput. Chem. 2004, 25, 1157-1174.

(60) Bayly, C. I.; Cieplak, P.; Cornell, W.; Kollman, P. A. A well-behaved electrostatic potential based method using charge restraints for deriving atomic charges: the RESP model. J. Phys. Chem. 1993, 97, 10269-10280.

(61) Cornell, W. D.; Cieplak, P.; Bayly, C. I.; Kollman, P. A. Application of RESP charges to calculate conformational energies, hydrogen bond energies, and free energies of solvation. J. Am. Chem. Soc. 1993, 115, 9620-9631.

(62) Gordon, M. S.; Schmidt, M. W. In Theory and Applications of Computational Chemistry: the first forty years; Dykstra, C. E., Frenking, G., Kim, K. S., Scuseria, G. E., Eds.; Elsevier: Amsterdam, 2005; pp 1167-1189.

(63) Mongan, J.; Simmerling, C.; McCammon, J. A.; Case, D. A.; Onufriev, A. Generalized Born Model with a Simple, Robust Molecular Volume Correction. J. Chem. Theory Comput. 2007, 3, 156-169.

(64) Weiser, J.; Shenkin, P. S.; Still, W. C. Approximate atomic surfaces from linear combinations of pairwise overlaps (LCPO). J. Comput. Chem. 1999, 20, 217-230.

(65) Sitkoff, D.; Sharp, K. A.; Honig, B. Accurate Calculation of Hydration Free Energies Using Macroscopic Solvent Models. J. Phys. Chem. 1994, 98, 1978-1988.

(66) Hopkins, C. W.; Le Grand, S.; Walker, R. C.; Roitberg, A. E. Long-Time-Step Molecular Dynamics through Hydrogen Mass Repartitioning. J. Chem. Theory Comput. 2015, 11, 1864-1874.

(67) Jorgensen, W. L.; Chandrasekhar, J.; Madura, J. D.; Impey, R. W.; Klein, M. L. Comparison of simple potential functions for simulating liquid water. J. Chem. Phys. 1983, 79, 926-935. 
(68) Berendsen, H. J. C.; Postma, J. P. M.; van Gunsteren, W. F.; DiNola, A.; Haak, J. R. Molecular dynamics with coupling to an external bath. J. Chem. Phys. 1984, 81, 36843690.

(69) Consortium, T. U. UniProt: a worldwide hub of protein knowledge. Nucleic Acids Res. 2019, 47, D506-D515.

(70) Needleman, S. B.; Wunsch, C. D. A general method applicable to the search for similarities in the amino acid sequence of two proteins. J. Mol. Biol. 1970, 48, 443-453.

(71) Madeira, F.; Park, Y. M.; Lee, J.; Buso, N.; Gur, T.; Madhusoodanan, N.; Basutkar, P.; Tivey, A. R. N.; Potter, S. C.; Finn, R. D.; Lopez, R. The EMBL-EBI search and sequence analysis tools APIs in 2019. Nucleic Acids Res. 2019, 47, W636-W641.

(72) Braka, A.; Garnier, N.; Bonnet, P.; Aci-Sèche, S. Residence Time Prediction of Type 1 and 2 Kinase Inhibitors from Unbinding Simulations. J. Chem. Inf. Model. 2020, 60, $342-348$.

(73) Zhang, D.; Huang, S.; Mei, H.; Kevin, M.; Shi, T.; Chen, L. Protein-ligand interaction fingerprints for accurate prediction of dissociation rates of p38 MAPK Type II inhibitors. Integr. Biol. 2019, 11, 53-60.

(74) Du, Y.; Wang, R. Revealing the Unbinding Kinetics and Mechanism of Type I and Type II Protein Kinase Inhibitors by Local-Scaled Molecular Dynamics Simulations. J. Chem. Theory Comput. 2020, 16, 6620-6632.

(75) Huang, S.; Chen, L.; Mei, H.; Zhang, D.; Shi, T.; Kuang, Z.; Heng, Y.; Xu, L.; Pan, X. In Silico Prediction of the Dissociation Rate Constants of Small Chemical Ligands by 3D-Grid-Based VolSurf Method. Int. J. Mol. Sci. 2020, 21.

(76) Amangeldiuly, N.; Karlov, D.; Fedorov, M. V. Baseline Model for Predicting Protein- 
Ligand Unbinding Kinetics through Machine Learning. J. Chem. Inf. Model. 2020, 60, $5946-5956$.

(77) Azam, M.; Latek, R. R.; Daley, G. Q. Mechanisms of autoinhibition and STI571/imatinib resistance revealed by mutagenesis of BCR-ABL. Cell 2003, 112, 831843.

(78) Ray, A.; Cowan-Jacob, S. W.; Manley, P. W.; Mestan, J.; Griffin, J. D. Identification of BCR-ABL point mutations conferring resistance to the Abl kinase inhibitor AMN107 (nilotinib) by a random mutagenesis study. Blood 2007, 109, 5011-5015.

(79) Hu, R.; Xu, H.; Jia, P.; Zhao, Z. KinaseMD: kinase mutations and drug response database. Nucleic Acids Res. 2021, 49, D552-D561.

(80) Sun, H.; Tian, S.; Zhou, S.; Li, Y.; Li, D.; Xu, L.; Shen, M.; Pan, P.; Hou, T. Revealing the favorable dissociation pathway of type II kinase inhibitors via enhanced sampling simulations and two-end-state calculations. Sci. Rep. 2015, 5, 8457.

(81) You, W.; Chang, C. A. Role of Molecular Interactions and Protein Rearrangement in the Dissociation Kinetics of p38 $\alpha$ MAP Kinase Type-I/II/III Inhibitors. J. Chem. Inf. Model. 2018, 58, 968-981. 


\title{
Prediction of Drug-Target Binding Kinetics for Flexible Proteins by Comparative Binding Energy Analysis
}

\author{
Ariane Nunes-Alves ${ }^{1,2, \ddagger}$, Fabian Ormersbach ${ }^{1}$, and Rebecca C. Wade ${ }^{1,2,3, \ddagger}$ \\ ${ }^{1}$ Heidelberg Institute for Theoretical Studies (HITS), Schloß-Wolfsbrunnenweg 35, 69118 \\ Heidelberg, Germany \\ ${ }^{2}$ Center for Molecular Biology (ZMBH), DKFZ-ZMBH Alliance, Heidelberg University, Im \\ Neuenheimer Feld 282, 69120 Heidelberg, Germany \\ ${ }^{3}$ Interdisciplinary Center for Scientific Computing (IWR), Heidelberg University, Im \\ Neuenheimer Feld 205, Heidelberg, Germany \\ ‡ariane.nunes-alves@h-its.org; rebecca.wade@h-its.org
}

\section{Supporting Information}




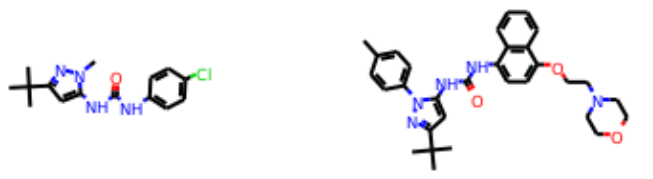

1<smiles>[TeH][TeH2]</smiles>

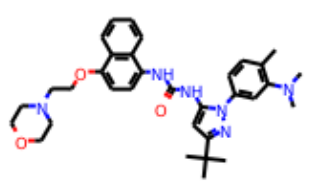<smiles>C[14CH2][14CH2]O</smiles>

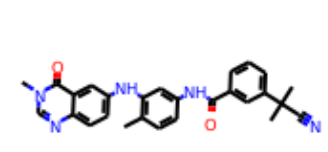

6

11

15<smiles>C[13CH]=[13CH]O</smiles>

7<smiles>C[14CH2][14CH2]O</smiles>

12

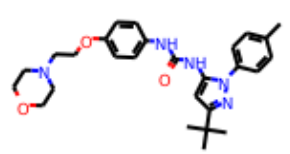

16

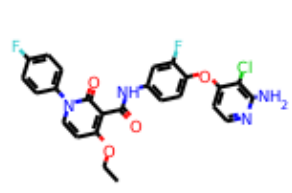

20

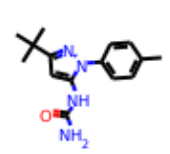

3

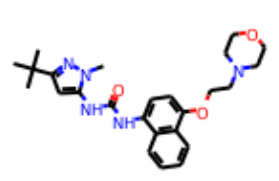

8<smiles>CC(C)OCCO</smiles>

13

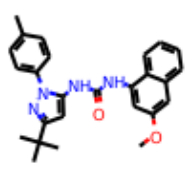

17

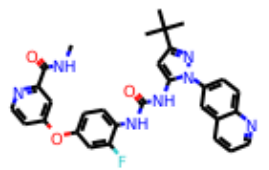

22

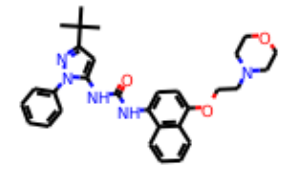

5

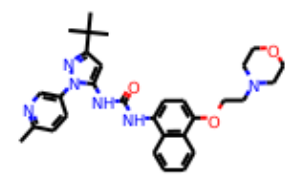

9

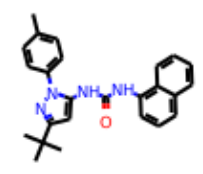

14

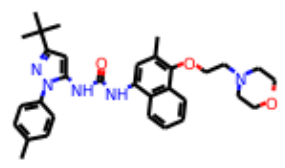

18

Figure S1: Chemical structures of the 33 inhibitors of p38 MAP kinase used for COMBINE analysis. 


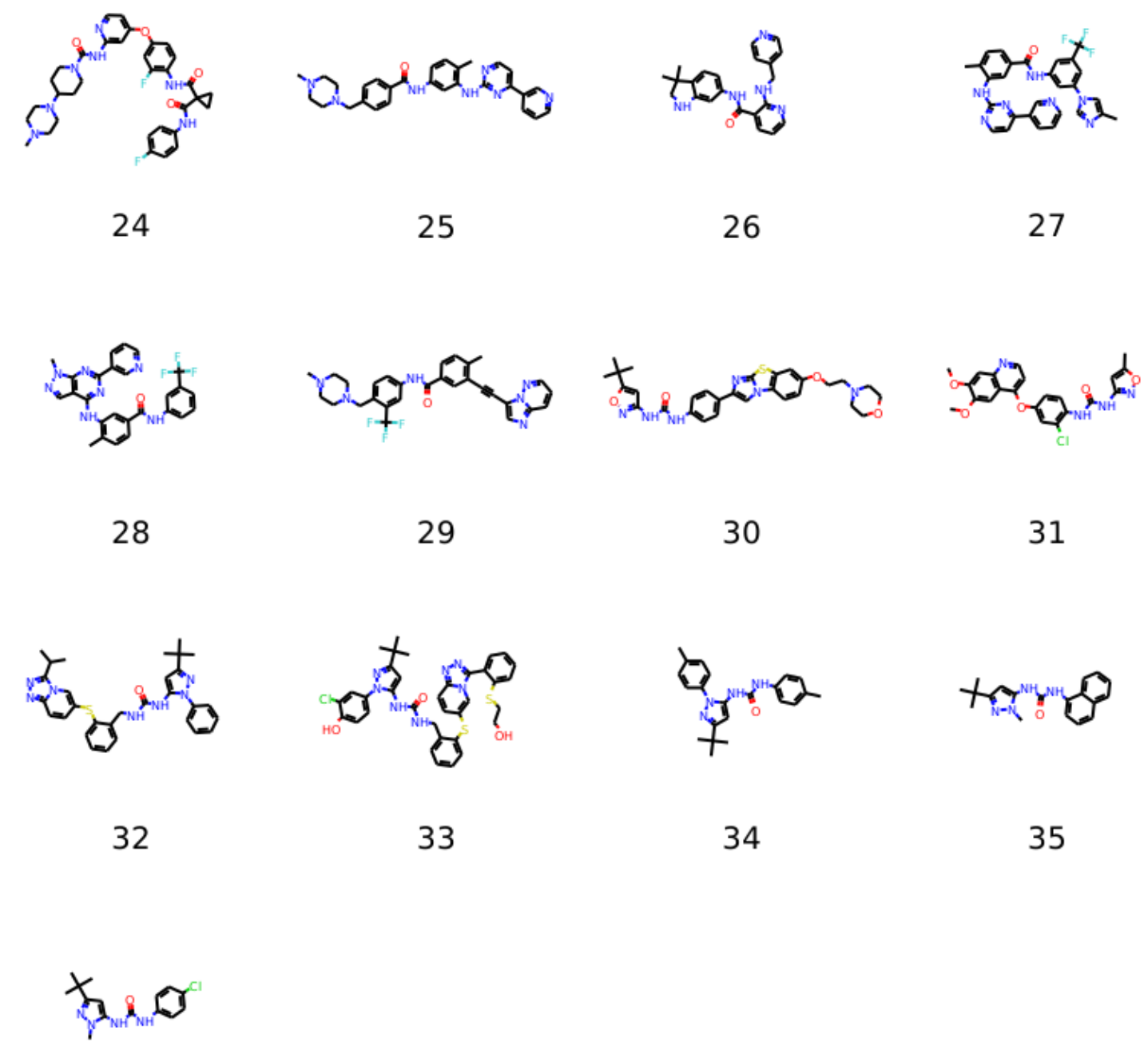

36

Figure S1: Continuation. 

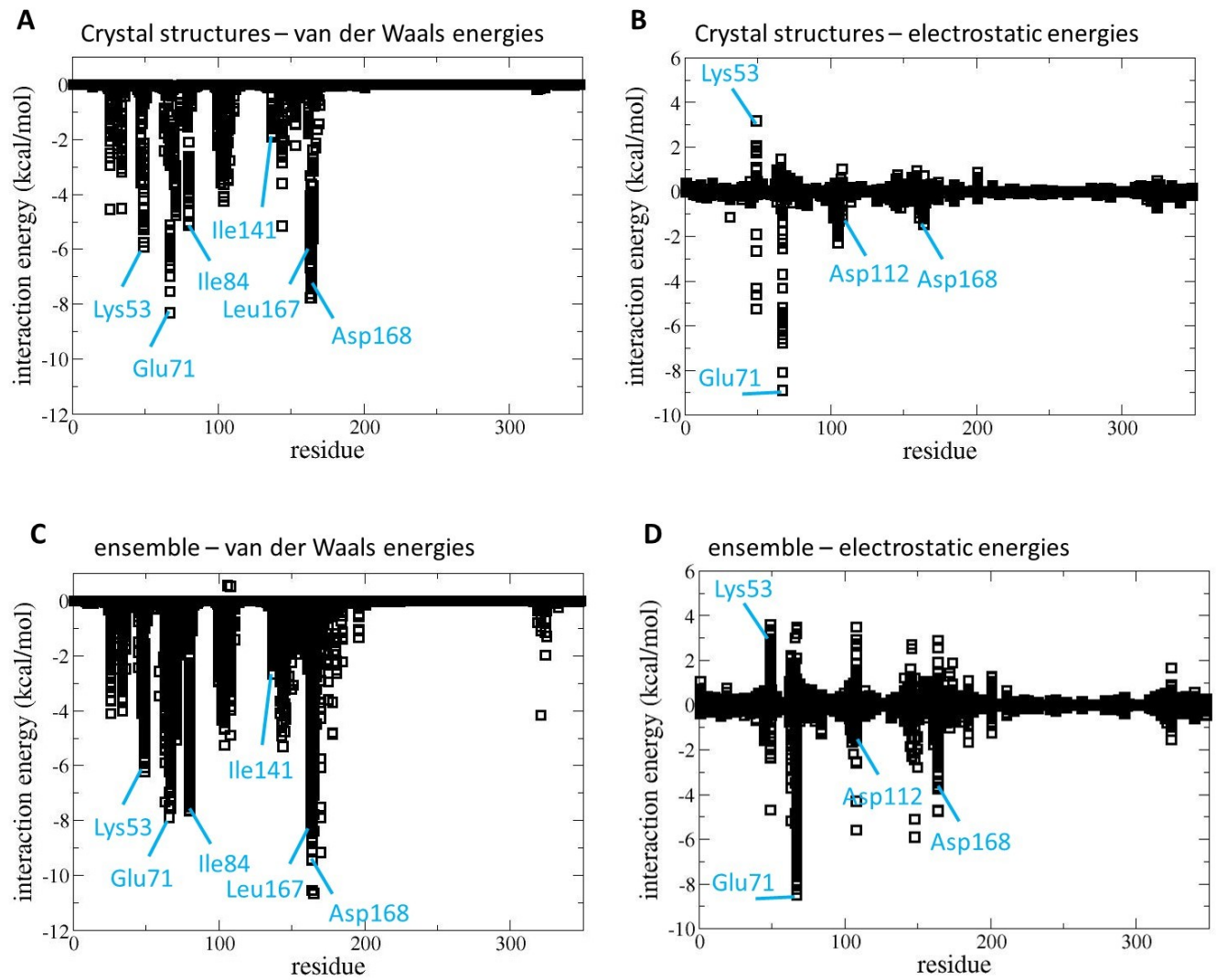

Figure S2: Interaction energies between p38 MAP kinase amino acid residues and inhibitors. Van der Waals (a, c) and electrostatic (b, d) interaction energies were computed between inhibitors and the 348 residues in p38 MAP kinase using the COMBINE program. Each column has 33 ( $\mathrm{a}, \mathrm{b}$ ) data points corresponding to the 33 inhibitors used for COMBINE analysis applied to single crystal structures or 330 data points (c, d) corresponding to the 330 ligand-protein complexes (10 complexes per ligand) used for COMBINE analysis applied to structures from ensemble docking. Selected residues are labelled. 

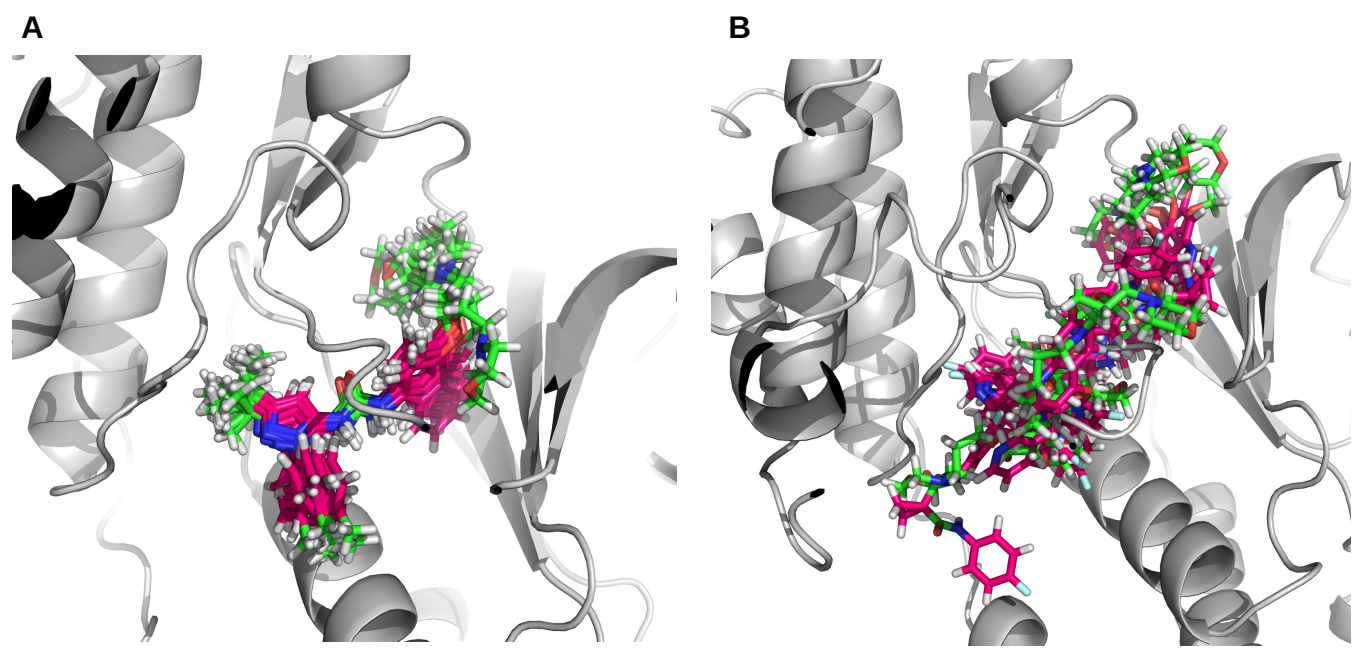

Figure S3: Ten binding modes obtained from ensemble docking for ligands 2 (a) and 23 (b). Protein backbone in gray (PDB 1KV2), ligand colored according to atom type. The binding modes were obtained from docking to ten different protein configurations using AutoDock Vina. 
A

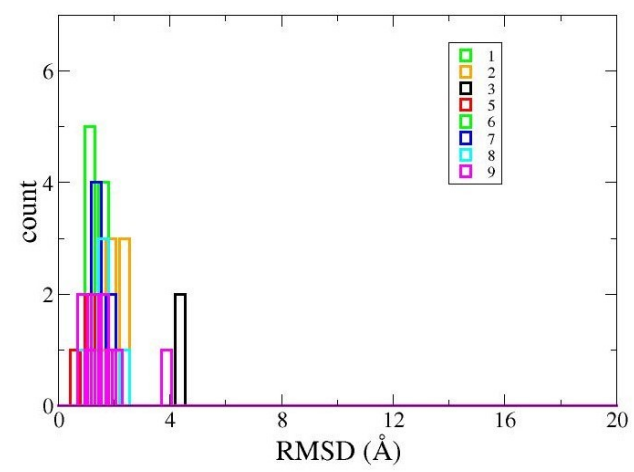

C

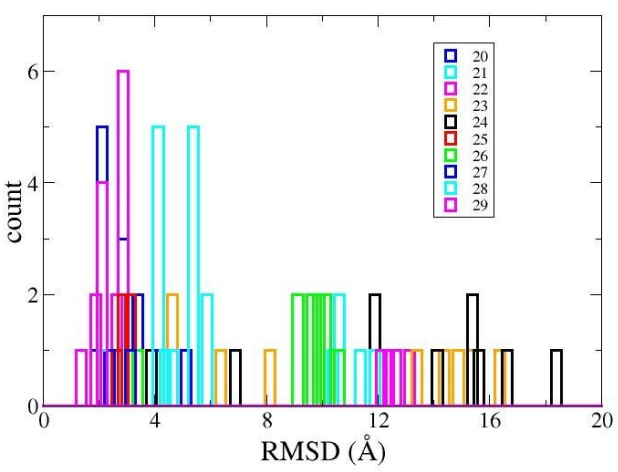

B

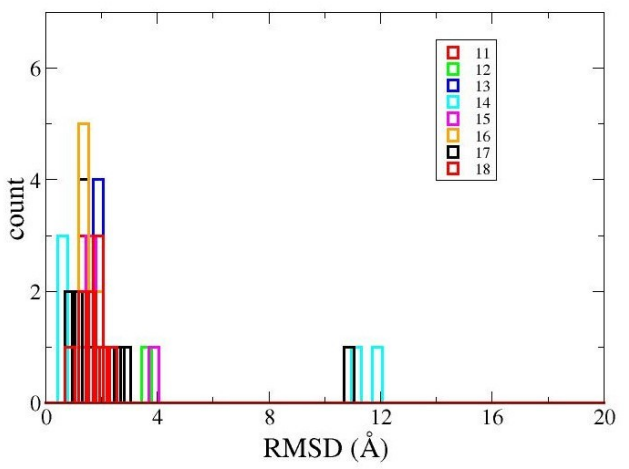

D

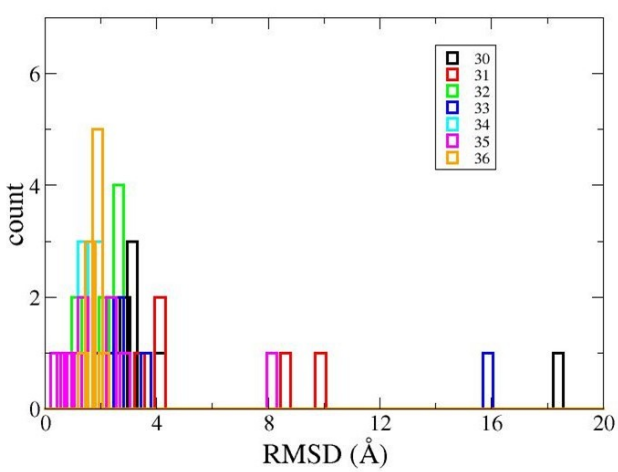

Figure S4: Histograms of root mean squared deviations (RMSD) between the ligand position in the crystal structure and the ligand position in the 10 complexes obtained from ensemble docking. (a) Ligands 1 to 9. (b) Ligands 11 to 18. (c) Ligands 20 to 29. (d) Ligands 30 to 36. Only heavy atoms were considered for RMSD calculation. 
A
Abl

B

p38

EGFR
33 GAYGSVCAAFDTKTGLRVAVKKLSRPFQSIIHAKRTYRELRLLKHMKHEN

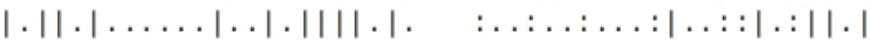
251 GQYGEVYEGWWKKYSLTVAVKTLK - - - EDTMEVEEFLKEAAVMKEIKHPN 54 KLSRPFQSI IHAKRTYRELRLLKHMKHENVIGLLDVFTPARSLEEFNDVY $:|| \ldots|\ldots| \ldots|\ldots| \ldots: \ldots: ., \ldots:|\ldots| \mid, . \ldots$ 746 EL-REATSPKANKEILDEAYVMASVDNPHVCRLLGICLT - . . . . . STVQ
82

297

103

787

Figure S5: Alignment of p38 MAP kinase with the human Abl kinase (a) or with the human EGFR kinase (b). (a) Positions 67 and 70 of p38 MAP kinase are highlighted in bold. Mutations in the equivalent positions in Abl kinase are associated with drug resistance. (b) Position 71 of p38 MAP kinase is highlighted in bold. Mutations in the equivalent position in EGFR kinase are associated with drug resistance. 
A

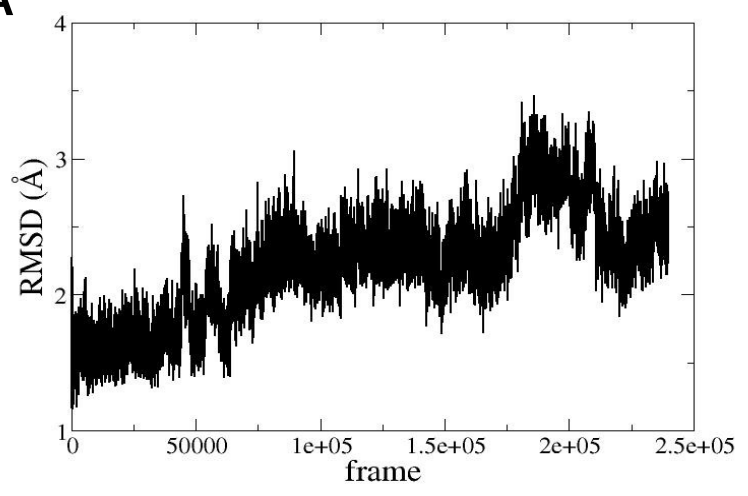

C

Single structures

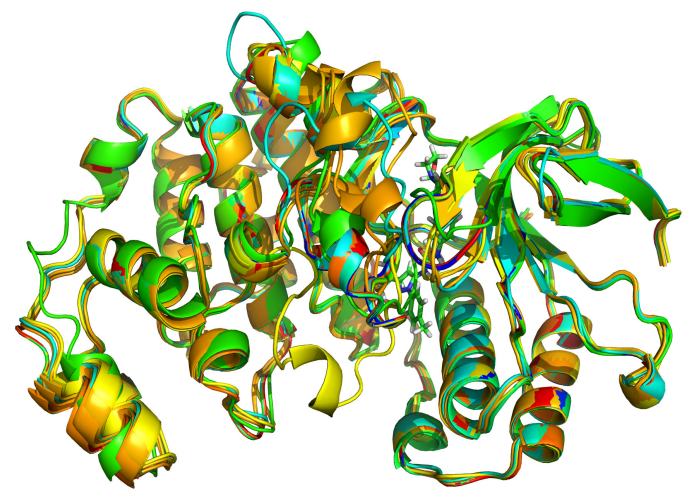

B

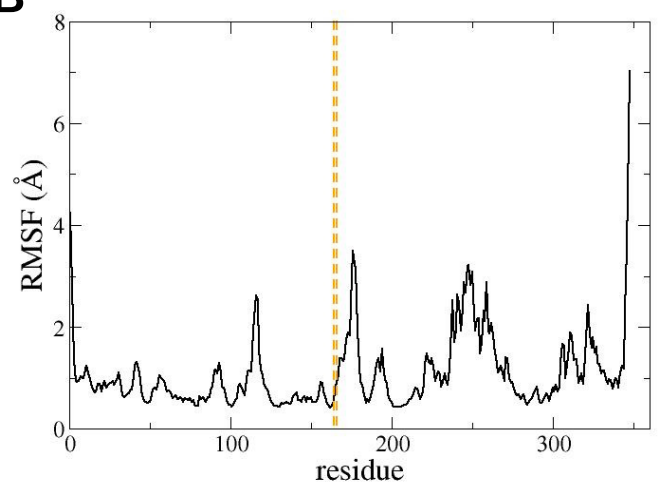

Ensemble

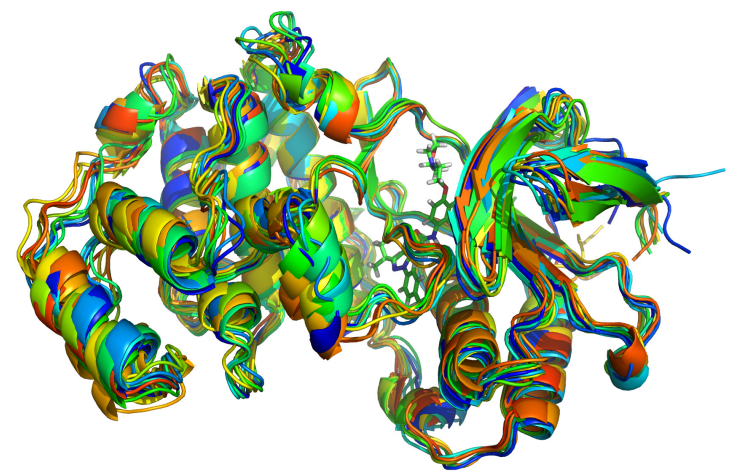

Figure S6: Structural variation of proteins in the models using single structures or an ensemble of structures to represent each ligand-protein complex. (a) Root mean squared deviation (RMSD) of p38 MAP kinase along the trajectory performed to obtain the ensemble. Only heavy atoms of the protein backbone were considered for RMSD calculation. (b) Root mean squared fluctuation (RMSF) of p38 MAP kinase in the trajectory performed to obtain the ensemble. Only $\mathrm{C} \alpha$ atoms were considered for RMSF calculation. Orange dashed lines highlight the position of the DFG motif. (c) Protein structures in the model using single structures or an ensemble to represent each ligand-protein complex. Ligand 16 is represented as sticks to show the position of the binding site. 
Table S1: List of the SMILES strings for the p38 MAP kinase inhibitors.

\begin{tabular}{|c|c|}
\hline inhibitor ID & SMILES \\
\hline 1 & $\mathrm{C}(=\mathrm{O})(\mathrm{Nc} 1 \mathrm{ccc}(\mathrm{Cl}) \operatorname{cc} 1) \mathrm{Nc} 1 \mathrm{cc}(\mathrm{nn} 1 \mathrm{C}) \mathrm{C}(\mathrm{C})(\mathrm{C}) \mathrm{C}$ \\
\hline 2 & $\begin{array}{l}\mathrm{C}(=\mathrm{O})(\mathrm{Nc} 1 \mathrm{c} 2 \mathrm{c}(\mathrm{c}(\mathrm{cc} 1) \mathrm{OCCN} 1 \mathrm{CCOCC} 1) \mathrm{cccc} 2) \mathrm{Nc} 1 \mathrm{cc}(\mathrm{nn} 1 \mathrm{c} 1 \mathrm{ccc}(\mathrm{cc} 1) \\
\mathrm{C}) \mathrm{C}(\mathrm{C})(\mathrm{C}) \mathrm{C}\end{array}$ \\
\hline 3 & $\operatorname{c1c}(\operatorname{ccc}(\mathrm{c} 1) \mathrm{C}) \mathrm{n} 1 \mathrm{c}(\mathrm{cc}(\mathrm{n} 1) \mathrm{C}(\mathrm{C})(\mathrm{C}) \mathrm{C}) \mathrm{NC}(=\mathrm{O}) \mathrm{N}$ \\
\hline 5 & $\begin{array}{l}\mathrm{C} 1 \mathrm{~N}(\mathrm{CCOC} 1) \mathrm{CCOc} 1 \mathrm{c} 2 \mathrm{c}(\mathrm{c}(\mathrm{cc} 1) \mathrm{NC}(=\mathrm{O}) \mathrm{Nc} 1 \mathrm{cc}(\mathrm{nn} 1 \mathrm{c} 1 \mathrm{ccccc} 1) \mathrm{C}(\mathrm{C}) \\
(\mathrm{C}) \mathrm{C}) \operatorname{cccc} 2\end{array}$ \\
\hline 6 & $\begin{array}{l}\mathrm{C} 1 \mathrm{~N}(\mathrm{CCOC} 1) \mathrm{CCOc} 1 \mathrm{c} 2 \mathrm{c}(\mathrm{c}(\mathrm{cc} 1) \mathrm{NC}(=\mathrm{O}) \mathrm{Nc} 1 \mathrm{cc}(\mathrm{nn} 1 \mathrm{c} 1 \mathrm{ccccc} 1) \mathrm{C}(\mathrm{C}) \\
\mathrm{C}) \operatorname{cccc} 2\end{array}$ \\
\hline 7 & $\begin{array}{l}\mathrm{c} 1 \mathrm{c}(\operatorname{ccc}(\mathrm{c} 1) \mathrm{C}) \mathrm{n} 1 \mathrm{c}(\mathrm{cc}(\mathrm{n} 1) \mathrm{C}(\mathrm{C})(\mathrm{C}) \mathrm{CO}) \mathrm{NC}(=\mathrm{O}) \mathrm{Nc} 1 \mathrm{c} 2 \mathrm{c}(\mathrm{c}(\mathrm{cc} 1) \\
\text { OCCN1CCOCC1)cccc2 }\end{array}$ \\
\hline 8 & $\begin{array}{l}\mathrm{C} 1 \mathrm{~N}(\mathrm{CCOC} 1) \mathrm{CCOc} 1 \mathrm{c} 2 \mathrm{c}(\mathrm{c}(\mathrm{cc} 1) \mathrm{NC}(=\mathrm{O}) \mathrm{Nc} 1 \mathrm{cc}(\mathrm{nn} 1 \mathrm{C}) \mathrm{C}(\mathrm{C})(\mathrm{C}) \mathrm{C}) \\
\mathrm{cccc} 2\end{array}$ \\
\hline 9 & $\begin{array}{l}\mathrm{C} 1 \mathrm{~N}(\mathrm{CCOC} 1) \mathrm{CCOc} 1 \mathrm{c} 2 \mathrm{c}(\mathrm{c}(\mathrm{cc} 1) \mathrm{NC}(=\mathrm{O}) \mathrm{Nc} 1 \mathrm{cc}(\mathrm{nn} 1 \mathrm{c} 1 \mathrm{cnc}(\mathrm{cc} 1) \mathrm{C}) \mathrm{C} \\
(\mathrm{C})(\mathrm{C}) \mathrm{C}) \mathrm{cccc} 2\end{array}$ \\
\hline 11 & $\begin{array}{l}\mathrm{C} 1 \mathrm{~N}(\mathrm{CCOC} 1) \mathrm{CCOc} 1 \mathrm{c} 2 \mathrm{c}(\mathrm{c}(\mathrm{cc} 1) \mathrm{NC}(=\mathrm{O}) \mathrm{Nc} 1 \mathrm{cc}(\mathrm{nn} 1 \mathrm{c} 1 \mathrm{cc}(\mathrm{c}(\mathrm{cc} 1) \mathrm{C}) \\
\mathrm{N}(\mathrm{C}) \mathrm{C}) \mathrm{C}(\mathrm{C})(\mathrm{C}) \mathrm{C}) \operatorname{cccc} 2\end{array}$ \\
\hline 12 & $\begin{array}{l}\mathrm{C} 1 \mathrm{~N}(\mathrm{CCOC} 1) \mathrm{CCOc} 1 \mathrm{c} 2 \mathrm{c}(\mathrm{c}(\mathrm{cc} 1) \mathrm{NC}(=\mathrm{O}) \mathrm{Nc} 1 \mathrm{cc}(\mathrm{nn} 1 \mathrm{c} 1 \mathrm{cc}(\mathrm{ccc} 1) \\
\mathrm{N}(\mathrm{C}) \mathrm{C}) \mathrm{C}(\mathrm{C})(\mathrm{C}) \mathrm{C}) \operatorname{cccc} 2\end{array}$ \\
\hline 13 & $\operatorname{c1cc}(\operatorname{ccc} 1) \mathrm{NC}(=\mathrm{O}) \mathrm{Nc} \ln (\mathrm{nc}(\mathrm{c} 1) \mathrm{C}(\mathrm{C})(\mathrm{C}) \mathrm{C}) \mathrm{c} 1 \mathrm{ccc}(\mathrm{cc} 1) \mathrm{C}$ \\
\hline 14 & $\mathrm{c} 1 \mathrm{c}(\mathrm{ccc}(\mathrm{c} 1) \mathrm{C}) \mathrm{n} 1 \mathrm{c}(\mathrm{cc}(\mathrm{n} 1) \mathrm{C}(\mathrm{C})(\mathrm{C}) \mathrm{C}) \mathrm{NC}(=\mathrm{O}) \mathrm{Nc} 1 \mathrm{c} 2 \mathrm{c}(\mathrm{ccc} 1) \mathrm{cccc} 2$ \\
\hline 15 & $\begin{array}{l}\mathrm{C} 1 \mathrm{~N}(\mathrm{CCOC} 1) \mathrm{CCCc} 1 \mathrm{c} 2 \mathrm{c}(\mathrm{c}(\mathrm{cc} 1) \mathrm{NC}(=\mathrm{O}) \mathrm{Nc} 1 \mathrm{cc}(\mathrm{nn} 1 \mathrm{c} 1 \mathrm{ccc}(\mathrm{cc} 1) \\
\mathrm{C}) \mathrm{C}(\mathrm{C})(\mathrm{C}) \mathrm{C}) \mathrm{cccc} 2\end{array}$ \\
\hline 16 & C1COCCN1CCOc1ccc(cc1)NC(=O)Nc1cc(C(C)(C)C)nn1c1ccc(C)cc1 \\
\hline 17 & $\operatorname{c1c} 2 \mathrm{c}(\operatorname{ccc} 1) \mathrm{c}(\mathrm{cc}(\mathrm{c} 2) \mathrm{OC}) \mathrm{NC}(=\mathrm{O}) \mathrm{Nc} 1 \mathrm{n}(\mathrm{nc}(\mathrm{c} 1) \mathrm{C}(\mathrm{C})(\mathrm{C}) \mathrm{C}) \mathrm{c} 1 \mathrm{ccc}(\mathrm{cc} 1) \mathrm{C}$ \\
\hline 18 & $\begin{array}{l}\mathrm{C} 1 \mathrm{~N}(\mathrm{CCOC} 1) \mathrm{CCOc} 1 \mathrm{c} 2 \mathrm{c}(\mathrm{c}(\mathrm{cc} 1 \mathrm{C}) \mathrm{NC}(=\mathrm{O}) \mathrm{Nc} 1 \mathrm{cc}(\mathrm{nn} 1 \mathrm{c} 1 \mathrm{ccc}(\mathrm{cc} 1) \mathrm{C}) \\
\mathrm{C}(\mathrm{C})(\mathrm{C}) \mathrm{C}) \operatorname{cccc} 2\end{array}$ \\
\hline 20 & $\begin{array}{l}\operatorname{c12c}(\operatorname{ccc}(\mathrm{c} 1) \mathrm{Nc} 1 \mathrm{c}(\operatorname{ccc}(\mathrm{c} 1) \mathrm{NC}(=\mathrm{O}) \mathrm{c} 1 \mathrm{cc}(\operatorname{ccc} 1) \mathrm{C}(\mathrm{C} \# \mathrm{~N})(\mathrm{C}) \mathrm{C}) \mathrm{C}) \\
\mathrm{ncn}(\mathrm{c} 2=\mathrm{O}) \mathrm{C}\end{array}$ \\
\hline 21 & $\operatorname{c1cc}(\operatorname{ccc} 1 n 1 \mathrm{ccc}(\mathrm{c}(\mathrm{c} 1=\mathrm{O}) \mathrm{C}(=\mathrm{O}) \mathrm{Nc} 1 \mathrm{ccc}(\mathrm{c}(\mathrm{c} 1) \mathrm{F}) \mathrm{Oc} 1 \mathrm{ccnc}(\mathrm{c} 1 \mathrm{Cl}) \mathrm{N}) \mathrm{OCC}) \mathrm{F}$ \\
\hline 22 & $\begin{array}{l}\mathrm{c} 1(\operatorname{ccc} 2 \mathrm{c}(\mathrm{c} 1) \operatorname{ccc} 2) \mathrm{n} 1 \mathrm{c}(\mathrm{cc}(\mathrm{n} 1) \mathrm{C}(\mathrm{C})(\mathrm{C}) \mathrm{C}) \mathrm{NC}(=\mathrm{O}) \mathrm{Nc} 1 \mathrm{ccc}(\mathrm{cc} 1 \mathrm{~F}) \\
\text { Oc1cc }(\mathrm{ncc} 1) \mathrm{C}(=\mathrm{O}) \mathrm{NC}\end{array}$ \\
\hline 23 & $\begin{array}{l}\mathrm{c} 1(\mathrm{c}(\mathrm{cc} 2 \mathrm{c}(\mathrm{c} 1) \mathrm{c}(\mathrm{ccn} 2) \mathrm{Oc} 1 \mathrm{ccc}(\mathrm{cc} 1 \mathrm{~F}) \mathrm{NC}(=\mathrm{O}) \mathrm{C} 1(\mathrm{C}(=\mathrm{O}) \mathrm{Nc} 2 \mathrm{ccc}(\mathrm{cc} 2) \mathrm{F}) \\
\mathrm{CC} 1) \mathrm{OCCCN} 1 \mathrm{CCOCC} 1) \mathrm{OC}\end{array}$ \\
\hline 24 & $\begin{array}{l}\mathrm{C} 1 \mathrm{CN}(\mathrm{C}) \mathrm{CCN} 1 \mathrm{C} 1 \mathrm{CCN}(\mathrm{CC} 1) \mathrm{C}(=\mathrm{O}) \mathrm{Nc} 1 \mathrm{cc}(\mathrm{ccn} 1) \mathrm{Oc} 1 \mathrm{cc}(\mathrm{F}) \mathrm{c}(\mathrm{cc} 1) \\
\mathrm{NC}(=\mathrm{O}) \mathrm{C} 1(\mathrm{CC} 1) \mathrm{C}(=\mathrm{O}) \mathrm{Nc} 1 \mathrm{ccc}(\mathrm{F}) \mathrm{cc} 1\end{array}$ \\
\hline 25 & $\begin{array}{l}\text { c1cc(cnc1)c1ccnc(n1) Nc1c(ccc(c1) NC(=O)c1ccc(cc1)CN1CCN(C) } \\
\text { CC1)C }\end{array}$ \\
\hline
\end{tabular}


Table S1: Continuation.

\begin{tabular}{|c|c|}
\hline inhibitor ID & SMILES \\
\hline 26 & $\mathrm{CC} 1(\mathrm{C}) \mathrm{CNc} 2 \mathrm{cc}(\operatorname{ccc} 12) \mathrm{NC}(=\mathrm{O}) \mathrm{c} 1 \mathrm{ccc} n \mathrm{~N} 1 \mathrm{NCc} 1 \mathrm{ccncc} 1$ \\
\hline 27 & $\begin{array}{l}\mathrm{O}=\mathrm{C}(\mathrm{Nc} 1 \mathrm{cc}(\mathrm{n} 2 \mathrm{cc}(\mathrm{C}) \mathrm{nc} 2) \mathrm{cc}(\mathrm{c} 1) \mathrm{C}(\mathrm{F})(\mathrm{F}) \mathrm{F}) \mathrm{c} 1 \mathrm{ccc}(\mathrm{C}) \mathrm{c}(\mathrm{c} 1) \mathrm{Nc} 1 \mathrm{nccc}(\mathrm{n} 1) \\
\mathrm{c} 1 \mathrm{cccnc} 1\end{array}$ \\
\hline 28 & $\operatorname{Cc} 1 \mathrm{c}(\mathrm{cc}(\mathrm{cc} 1) \mathrm{C}(=\mathrm{O}) \mathrm{Nc} 1 \mathrm{cccc}(\mathrm{c} 1) \mathrm{C}(\mathrm{F})(\mathrm{F}) \mathrm{F}) \mathrm{Nc} 1 \mathrm{nc}(\mathrm{nc} 2 \mathrm{c} 1 \mathrm{cnn} 2 \mathrm{C}) \mathrm{c} 1 \mathrm{cnccc} 1$ \\
\hline 29 & $\begin{array}{l}\text { n1c2cccnn2c(c1)C\#Cc1c }(\operatorname{ccc}(\mathrm{c} 1) \mathrm{C}(=\mathrm{O}) \operatorname{Nc} 1 \mathrm{ccc}(\mathrm{c}(\mathrm{c} 1) \mathrm{C}(\mathrm{F})(\mathrm{F}) \mathrm{F}) \\
\mathrm{CN} 1 \mathrm{CCN}(\mathrm{CC} 1) \mathrm{C}) \mathrm{C}\end{array}$ \\
\hline 30 & $\begin{array}{l}\mathrm{N}(\mathrm{C}(=\mathrm{O}) \mathrm{Nc} 1 \mathrm{ccc}(\mathrm{cc} 1) \mathrm{c} 1 \mathrm{cn} 2 \mathrm{c}(\mathrm{n} 1) \mathrm{sc} 1 \mathrm{c} 2 \mathrm{ccc}(\mathrm{c} 1) \mathrm{OCCN} 1 \mathrm{CCOCC} 1) \mathrm{c} 1 \mathrm{noc} \\
(\mathrm{c} 1) \mathrm{C}(\mathrm{C})(\mathrm{C}) \mathrm{C}\end{array}$ \\
\hline 31 & $\mathrm{c} 1(\operatorname{cc} 2 \mathrm{c}(\operatorname{cc} 1 \mathrm{OC}) \mathrm{c}(\mathrm{ccn} 2) \mathrm{Oc} 1 \mathrm{cc}(\mathrm{c}(\mathrm{cc} 1) \mathrm{NC}(=\mathrm{O}) \mathrm{Nc} 1 \mathrm{cc}($ on 1$) \mathrm{C}) \mathrm{Cl}) \mathrm{OC}$ \\
\hline 32 & $\begin{array}{l}\mathrm{CC}(\mathrm{C}) \mathrm{c} 1 \mathrm{nnn} 2 \operatorname{ccc}(\mathrm{Sc} 3 \operatorname{cccc} 3 \mathrm{CNC}(=\mathrm{O}) \mathrm{Nc} 3 \operatorname{cc}(\mathrm{nn} 3 \mathrm{c} 3 \operatorname{cccc} 3) \mathrm{C}(\mathrm{C})(\mathrm{C}) \mathrm{C}) \\
\mathrm{cn} 12\end{array}$ \\
\hline 33 & $\begin{array}{l}\mathrm{CC}(\mathrm{C})(\mathrm{C}) \mathrm{c} 1 \mathrm{cc}(\mathrm{NC}(=\mathrm{O}) \mathrm{NCc} 2 \mathrm{cccc} 2 \mathrm{Sc} 2 \mathrm{ccc} 3 \mathrm{nnn}(\mathrm{c} 4 \mathrm{ccccc} 4 \mathrm{SCCO}) \mathrm{n} 3 \mathrm{c} 2) \\
\mathrm{n}(\mathrm{n} 1) \mathrm{c} 1 \mathrm{ccc}(\mathrm{O}) \mathrm{c}(\mathrm{Cl}) \mathrm{c} 1\end{array}$ \\
\hline 34 & $\mathrm{c} 1 \mathrm{c}(\mathrm{ccc}(\mathrm{c} 1) \mathrm{C}) \mathrm{n} 1 \mathrm{c}(\mathrm{cc}(\mathrm{n} 1) \mathrm{C}(\mathrm{C})(\mathrm{C}) \mathrm{C}) \mathrm{NC}(=\mathrm{O}) \mathrm{Nc} 1 \mathrm{ccc}(\mathrm{cc} 1) \mathrm{C}$ \\
\hline 35 & $\mathrm{c} 1 \mathrm{c} 2 \mathrm{c}(\mathrm{ccc} 1) \mathrm{c}(\mathrm{ccc} 2) \mathrm{NC}(=\mathrm{O}) \mathrm{Nc} 1 \mathrm{n}(\mathrm{nc}(\mathrm{c} 1) \mathrm{C}(\mathrm{C})(\mathrm{C}) \mathrm{C}) \mathrm{C}$ \\
\hline 36 & $\mathrm{c} 1 \mathrm{c}(\mathrm{ccc}(\mathrm{c} 1) \mathrm{Cl}) \mathrm{NC}(=\mathrm{O}) \mathrm{Nc} 1 \mathrm{n}(\mathrm{nc}(\mathrm{c} 1) \mathrm{C}(\mathrm{C})(\mathrm{C}) \mathrm{C}) \mathrm{C}$ \\
\hline
\end{tabular}


Table S2: List of the PDB identifiers of crystal structures and $\mathrm{k}_{\text {off }}$ values $\left(\right.$ in $\mathrm{s}^{-1}$ ) for the p38 MAP kinase inhibitors.

\begin{tabular}{|c|c|c|c|c|}
\hline inhibitor ID & $\mathrm{PDB}^{a}$ & ref. $^{b} \mathrm{PDB}$ & experimental $\mathrm{k}_{o f f}$ & ref. $\mathrm{k}_{o f f}$ \\
\hline 1 & 1KV1 & 24 & $1.40 \mathrm{E}-01$ & 24 \\
\hline 2 & 1KV2 & 24 & 8.30E-06 & 26 \\
\hline $3^{*}$ & - & - & 1.40E-01 & 26 \\
\hline $5^{*}$ & - & - & $1.50 \mathrm{E}-05$ & 26 \\
\hline $6^{*}$ & - & - & $3.80 \mathrm{E}-04$ & 26 \\
\hline 7 & - & - & 4.00E-04 & 26 \\
\hline 8 & - & - & $3.30 \mathrm{E}-03$ & 26 \\
\hline 9 & - & - & $2.30 \mathrm{E}-05$ & 26 \\
\hline 11 & - & - & $3.80 \mathrm{E}-05$ & 26 \\
\hline $12^{*}$ & - & - & $2.60 \mathrm{E}-05$ & 26 \\
\hline 13 & - & - & 1.60E-03 & 26 \\
\hline $14^{*}$ & - & - & 1.20E-04 & 26 \\
\hline 15 & - & - & $2.30 \mathrm{E}-05$ & 26 \\
\hline $16^{*}$ & $3 H V 6$ & 34 & $3.90 \mathrm{E}-03$ & 26 \\
\hline 17 & - & - & $3.40 \mathrm{E}-04$ & 26 \\
\hline 18 & - & - & $1.50 \mathrm{E}-04$ & 26 \\
\hline 20 & 4RZW & 43 & 1.13E-02 & 29 \\
\hline $21^{*}$ & $3 F 82$ & 44 & 9.03E-02 & 29 \\
\hline 22 & 3QRI & 45 & $4.88 \mathrm{E}-04$ & 29 \\
\hline 23 & 3LQ8 & 46 & $9.10 \mathrm{E}-02$ & 29 \\
\hline $24^{*}$ & 5IA5 & 47 & $1.21 \mathrm{E}-01$ & 29 \\
\hline 25 & 3HEC & 35 & $1.31 \mathrm{E}-01$ & 29 \\
\hline 26 & 3EFL & - & 7.34E-02 & 29 \\
\hline 27 & 3PG0 & - & 8.96E-03 & 29 \\
\hline $28^{*}$ & $6 \mathrm{FNI}$ & 48 & $3.18 \mathrm{E}-02$ & 29 \\
\hline 29 & 4U0I & 49 & $4.82 \mathrm{E}-03$ & 29 \\
\hline 30 & 4RT7 & 50 & $5.20 \mathrm{E}-02$ & 29 \\
\hline 31 & 4ASE & 51 & $9.68 \mathrm{E}-02$ & 29 \\
\hline 32 & $2 \mathrm{YIW}$ & 27 & 4.00E-05 & 27 \\
\hline 33 & 2YIS & 27 & $2.40 \mathrm{E}-06$ & 27 \\
\hline $34^{*}$ & - & - & 1.00E-03 & 28 \\
\hline $35^{*}$ & - & - & $9.00 \mathrm{E}-03$ & 28 \\
\hline 36 & - & - & 2.80E-02 & 28 \\
\hline
\end{tabular}

*: inhibitors which were assigned to the test set. ${ }^{a}$ Bold: ligand in complex with p38 MAP kinase; others: ligand in complex with other kinases (the binding mode was used as a reference). For ligands without crystal structures, the binding mode of ligand 16 was used as a reference. ${ }^{b}$ ref.: reference. 
Table S3: Root mean squared deviation (RMSD) between the ligand position in the crystal structure and the ligand position obtained from redocking or cross-docking to the p38 MAP kinase structures in PDBs 1KV2 or 3HV6 using Vina. Only heavy atoms were considered for the RMSD calculation.

\begin{tabular}{lcc|cc}
\hline & \multicolumn{2}{c|}{ redocking } & \multicolumn{2}{c}{ cross-docking } \\
ligand & PDB & RMSD $(\AA)$ & PDB & RMSD $(\AA)$ \\
\hline 2 & 1KV2 & 1.05 & 3HV6 & 1.20 \\
16 & $3 \mathrm{HV} 6$ & 1.02 & 1KV2 & 1.80 \\
\hline
\end{tabular}

Table S4: Summary of the models derived for different numbers of latent variables (LVs) for COMBINE analysis for log $\mathrm{k}_{\text {off }}$ of p38 MAP kinase inhibitors using crystal structures (one structure per ligand). The table lists the coefficient of determination for the training and test sets $\left(\mathrm{R}^{2} \operatorname{tr}\right.$ and $\mathrm{R}^{2}$ te), the coefficient of determination for leave-one-out cross-validation set $\left(\mathrm{Q}^{2}\right.$-LOO), average absolute errors (AAEtr, AAEv and AAEte, in log $\mathrm{s}^{-1}$ ) and root mean squared errors (RMEtr, RMEv, and RMEte, in $\log \mathrm{s}^{-1}$ ) for the training set, leave-one-out cross-validation set, and test set, respectively. The model with 2 LVs (in bold) displayed the best balance between predictive performance and number of LVs.

\begin{tabular}{lccccccccc}
\hline $\mathrm{LV}$ & $\mathrm{R}^{2} \operatorname{tr}$ & $\mathrm{Q}^{2}$-LOO & AAEtr & AAEv & RMEtr & RMEv & R $^{2}$ te & AAEte & RMEte \\
\hline 1 & 0.83 & 0.72 & 0.52 & 0.66 & 0.62 & 0.79 & 0.77 & 0.49 & 0.68 \\
$\mathbf{2}$ & $\mathbf{0 . 8 6}$ & $\mathbf{0 . 7 5}$ & $\mathbf{0 . 4 9}$ & $\mathbf{0 . 6 8}$ & $\mathbf{0 . 5 5}$ & $\mathbf{0 . 7 5}$ & $\mathbf{0 . 7 9}$ & $\mathbf{0 . 5 4}$ & $\mathbf{0 . 6 4}$ \\
3 & 0.91 & 0.68 & 0.35 & 0.70 & 0.44 & 0.85 & 0.77 & 0.57 & 0.67 \\
4 & 0.94 & 0.66 & 0.29 & 0.70 & 0.37 & 0.87 & 0.72 & 0.59 & 0.75 \\
5 & 0.95 & 0.65 & 0.28 & 0.75 & 0.35 & 0.88 & 0.69 & 0.65 & 0.79 \\
6 & 0.96 & 0.57 & 0.23 & 0.84 & 0.30 & 0.98 & 0.65 & 0.65 & 0.84 \\
7 & 0.97 & 0.41 & 0.19 & 0.93 & 0.26 & 1.15 & 0.49 & 0.80 & 1.00 \\
8 & 0.98 & 0.28 & 0.15 & 0.98 & 0.22 & 1.27 & 0.50 & 0.76 & 1.00 \\
9 & 0.98 & 0.21 & 0.12 & 1.05 & 0.19 & 1.33 & 0.38 & 0.82 & 1.11 \\
10 & 0.99 & 0.18 & 0.12 & 1.08 & 0.17 & 1.35 & 0.24 & 0.91 & 1.23 \\
\hline
\end{tabular}


Table S5: Summary of the models derived for different numbers of latent variables (LVs) for COMBINE analysis for log $\mathrm{k}_{\text {off }}$ of p38 MAP kinase inhibitors using structures from ensemble docking (10 structures per ligand). The table lists the coefficient of determination for the training and test sets $\left(\mathrm{R}^{2} \operatorname{tr}\right.$ and $\mathrm{R}^{2}$ te), the coefficient of determination for leave-one-out cross-validation set $\left(\mathrm{Q}^{2}-\mathrm{LOO}\right)$, average absolute errors (AAEtr, AAEv and AAEte, in log $\mathrm{s}^{-1}$ ) and root mean squared errors (RMEtr, RMEv, and RMEte, in $\log \mathrm{s}^{-1}$ ) for the training set, leave-one-out cross-validation set, and test set, respectively. The model with $1 \mathrm{LV}$ (in bold) displayed the best balance between predictive performance and number of LVs.

\begin{tabular}{lccccccccc}
\hline LV & $\mathrm{R}^{2}$ tr & $\mathrm{Q}^{2}$-LOO & AAEtr & AAEv & RMEtr & RMEv & R $^{2}$ te & AAEte & RMEte \\
\hline $\mathbf{1}$ & $\mathbf{0 . 8 3}$ & $\mathbf{0 . 7 0}$ & $\mathbf{0 . 5 6}$ & $\mathbf{0 . 6 8}$ & $\mathbf{0 . 6 9}$ & $\mathbf{0 . 8 2}$ & $\mathbf{0 . 7 2}$ & $\mathbf{0 . 6 5}$ & $\mathbf{0 . 7 4}$ \\
2 & 0.79 & 0.67 & 0.55 & 0.68 & 0.71 & 0.86 & 0.62 & 0.75 & 0.87 \\
3 & 0.87 & 0.71 & 0.49 & 0.69 & 0.57 & 0.80 & 0.69 & 0.71 & 0.79 \\
4 & 0.89 & 0.70 & 0.44 & 0.70 & 0.51 & 0.81 & 0.65 & 0.73 & 0.83 \\
5 & 0.90 & 0.70 & 0.44 & 0.73 & 0.49 & 0.81 & 0.67 & 0.73 & 0.81 \\
6 & 0.92 & 0.73 & 0.40 & 0.69 & 0.45 & 0.77 & 0.75 & 0.63 & 0.71 \\
7 & 0.92 & 0.74 & 0.38 & 0.69 & 0.44 & 0.77 & 0.75 & 0.64 & 0.71 \\
8 & 0.93 & 0.74 & 0.37 & 0.69 & 0.41 & 0.76 & 0.77 & 0.59 & 0.68 \\
9 & 0.93 & 0.73 & 0.35 & 0.69 & 0.40 & 0.77 & 0.72 & 0.65 & 0.74 \\
10 & 0.94 & 0.73 & 0.33 & 0.69 & 0.39 & 0.78 & 0.72 & 0.66 & 0.74 \\
\hline
\end{tabular}

Table S6: Summary of the models derived for different numbers of latent variables (LVs) for COMBINE analysis for $\log \mathrm{k}_{\text {off }}$ of p38 MAP kinase inhibitors using structures from ensemble docking (1 structure per ligand; the top structure was selected using Vina scores). The table lists the coefficient of determination for the training and test sets $\left(R^{2} \operatorname{tr}\right.$ and $R^{2}$ te), the coefficient of determination for leave-one-out cross-validation set ( $\mathrm{Q}^{2}$-LOO), average absolute errors (AAEtr, AAEv and AAEte, in $\log \mathrm{s}^{-1}$ ) and root mean squared errors (RMEtr, RMEv, and RMEte, in $\log \mathrm{s}^{-1}$ ) for the training set, leave-one-out cross-validation set, and test set, respectively. The model with $2 \mathrm{LVs}$ (in bold) displayed the best balance between predictive performance and number of LVs.

\begin{tabular}{lccccccccc}
\hline LV & $\mathrm{R}^{2}$ tr & $\mathrm{Q}^{2}$-LOO & AAEtr & AAEv & RMEtr & RMEv & R $^{2}$ te & AAEte & RMEte \\
\hline 1 & 0.77 & 0.60 & 0.62 & 0.78 & 0.72 & 0.94 & 0.83 & 0.48 & 0.58 \\
$\mathbf{2}$ & $\mathbf{0 . 8 3}$ & $\mathbf{0 . 6 5}$ & $\mathbf{0 . 5 3}$ & $\mathbf{0 . 7 3}$ & $\mathbf{0 . 6 2}$ & $\mathbf{0 . 8 8}$ & $\mathbf{0 . 8 0}$ & $\mathbf{0 . 4 9}$ & $\mathbf{0 . 6 3}$ \\
3 & 0.90 & 0.59 & 0.40 & 0.81 & 0.46 & 0.96 & 0.82 & 0.45 & 0.60 \\
4 & 0.92 & 0.61 & 0.33 & 0.78 & 0.41 & 0.93 & 0.84 & 0.41 & 0.57 \\
5 & 0.94 & 0.61 & 0.30 & 0.79 & 0.38 & 0.93 & 0.83 & 0.40 & 0.58 \\
6 & 0.94 & 0.61 & 0.26 & 0.81 & 0.36 & 0.94 & 0.83 & 0.40 & 0.59 \\
7 & 0.96 & 0.53 & 0.21 & 0.88 & 0.31 & 1.02 & 0.77 & 0.42 & 0.68 \\
8 & 0.96 & 0.34 & 0.19 & 0.99 & 0.29 & 1.21 & 0.65 & 0.55 & 0.83 \\
9 & 0.97 & 0.22 & 0.17 & 1.01 & 0.24 & 1.32 & 0.27 & 0.80 & 1.21 \\
10 & 0.98 & 0.13 & 0.16 & 1.01 & 0.21 & 1.39 & -0.15 & 0.96 & 1.51 \\
\hline
\end{tabular}


Table S7: Summary of the models derived for different numbers of latent variables (LVs) for COMBINE analysis for $\log \mathrm{k}_{\text {off }}$ of $\mathrm{p} 38$ MAP kinase inhibitors using structures from ensemble docking (20 structures per ligand). The table lists the coefficient of determination for the training and test sets $\left(R^{2} \operatorname{tr}\right.$ and $R^{2}$ te), the coefficient of determination for leave-one-out cross-validation set $\left(\mathrm{Q}^{2}\right.$-LOO), average absolute errors (AAEtr, AAEv and AAEte, in log $\mathrm{s}^{-1}$ ) and root mean squared errors (RMEtr, RMEv, and RMEte, in $\log \mathrm{s}^{-1}$ ) for the training set, leave-one-out cross-validation set, and test set, respectively. The model with 1 LV (in bold) displayed the best balance between predictive performance and number of LVs.

\begin{tabular}{lccccccccc}
\hline LV & $\mathrm{R}^{2}$ tr & $\mathrm{Q}^{2}$-LOO & AAEtr & AAEv & RMEtr & RMEv & $\mathrm{R}^{2}$ te & AAEte & RMEte \\
\hline $\mathbf{1}$ & $\mathbf{0 . 8 4}$ & $\mathbf{0 . 6 5}$ & $\mathbf{0 . 6 3}$ & $\mathbf{0 . 7 5}$ & $\mathbf{0 . 7 5}$ & $\mathbf{0 . 8 8}$ & $\mathbf{0 . 7 1}$ & $\mathbf{0 . 6 6}$ & $\mathbf{0 . 7 6}$ \\
2 & 0.77 & 0.62 & 0.59 & 0.72 & 0.76 & 0.93 & 0.59 & 0.78 & 0.90 \\
3 & 0.82 & 0.60 & 0.56 & 0.79 & 0.66 & 0.95 & 0.60 & 0.80 & 0.89 \\
4 & 0.88 & 0.61 & 0.46 & 0.75 & 0.56 & 0.93 & 0.65 & 0.73 & 0.83 \\
5 & 0.90 & 0.64 & 0.44 & 0.76 & 0.50 & 0.90 & 0.71 & 0.67 & 0.76 \\
6 & 0.92 & 0.71 & 0.39 & 0.67 & 0.47 & 0.80 & 0.75 & 0.61 & 0.71 \\
7 & 0.92 & 0.73 & 0.39 & 0.65 & 0.46 & 0.77 & 0.76 & 0.60 & 0.69 \\
8 & 0.93 & 0.74 & 0.38 & 0.65 & 0.44 & 0.76 & 0.76 & 0.59 & 0.70 \\
9 & 0.93 & 0.75 & 0.36 & 0.65 & 0.43 & 0.75 & 0.73 & 0.64 & 0.73 \\
10 & 0.93 & 0.73 & 0.36 & 0.67 & 0.42 & 0.78 & 0.74 & 0.63 & 0.72 \\
\hline
\end{tabular}

Table S8: Summary of the models derived for different numbers of latent variables (LVs) for COMBINE analysis for $\log \mathrm{K}_{d}$ of p38 MAP kinase inhibitors using crystal structures (one structure per ligand). The table lists the coefficient of determination for the training and test sets $\left(\mathrm{R}^{2} \operatorname{tr}\right.$ and $\mathrm{R}^{2}$ te), the coefficient of determination for leave-one-out cross-validation set $\left(\mathrm{Q}^{2}\right.$-LOO), average absolute errors (AAEtr, AAEv and AAEte, in $\log \mathrm{s}^{-1}$ ) and root mean squared errors (RMEtr, RMEv, and RMEte, in $\log \mathrm{s}^{-1}$ ) for the training set, leave-one-out cross-validation set, and test set, respectively.

\begin{tabular}{lccccccccc}
\hline LV & $\mathrm{R}^{2}$ tr & $\mathrm{Q}^{2}$-LOO & AAEtr & AAEv & RMEtr & RMEv & $\mathrm{R}^{2}$ te & AAEte & RMEte \\
\hline 1 & 0.64 & 0.38 & 0.75 & 1.01 & 0.97 & 1.26 & 0.37 & 0.93 & 1.22 \\
2 & 0.78 & 0.46 & 0.67 & 0.99 & 0.75 & 1.17 & 0.39 & 1.05 & 1.21 \\
3 & 0.87 & 0.57 & 0.50 & 0.89 & 0.57 & 1.05 & 0.44 & 0.95 & 1.16 \\
4 & 0.90 & 0.60 & 0.42 & 0.90 & 0.50 & 1.02 & 0.27 & 1.00 & 1.33 \\
5 & 0.92 & 0.53 & 0.37 & 0.98 & 0.45 & 1.09 & 0.08 & 1.06 & 1.49 \\
6 & 0.94 & 0.50 & 0.29 & 1.01 & 0.39 & 1.14 & -0.19 & 1.17 & 1.69 \\
7 & 0.96 & 0.47 & 0.24 & 1.02 & 0.33 & 1.16 & -0.34 & 1.21 & 1.79 \\
8 & 0.98 & 0.35 & 0.19 & 1.12 & 0.25 & 1.29 & -0.93 & 1.38 & 2.15 \\
9 & 0.98 & 0.31 & 0.16 & 1.17 & 0.21 & 1.33 & -1.15 & 1.43 & 2.27 \\
10 & 0.99 & 0.31 & 0.13 & 1.20 & 0.19 & 1.33 & -1.36 & 1.48 & 2.38 \\
\hline
\end{tabular}


Table S9: Summary of the models derived for different numbers of latent variables (LVs) for COMBINE analysis for $\log \mathrm{K}_{d}$ of p38 MAP kinase inhibitors using structures from ensemble docking (10 structures per ligand). The table lists the coefficient of determination for the training and test sets $\left(\mathrm{R}^{2} \operatorname{tr}\right.$ and $\mathrm{R}^{2}$ te), the coefficient of determination for leave-one-out cross-validation set $\left(\mathrm{Q}^{2}\right.$-LOO), average absolute errors (AAEtr, AAEv and AAEte, in log $\mathrm{s}^{-1}$ ) and root mean squared errors (RMEtr, RMEv, and RMEte, in $\log \mathrm{s}^{-1}$ ) for the training set, leave-one-out cross-validation set, and test set, respectively.

\begin{tabular}{lccccccccc}
\hline $\mathrm{LV}$ & $\mathrm{R}^{2} \mathrm{tr}$ & $\mathrm{Q}^{2}$-LOO & AAEtr & AAEv & RMEtr & RMEv & $\mathrm{R}^{2}$ te & AAEte & RMEte \\
\hline 1 & 0.56 & 0.34 & 0.88 & 1.05 & 1.10 & 1.31 & 0.27 & 1.06 & 1.32 \\
2 & 0.57 & 0.27 & 0.86 & 1.09 & 1.06 & 1.37 & 0.19 & 1.10 & 1.39 \\
3 & 0.71 & 0.24 & 0.75 & 1.13 & 0.90 & 1.40 & 0.35 & 1.04 & 1.25 \\
4 & 0.74 & 0.19 & 0.71 & 1.15 & 0.86 & 1.45 & 0.32 & 1.02 & 1.28 \\
5 & 0.76 & 0.16 & 0.67 & 1.14 & 0.82 & 1.47 & 0.32 & 1.01 & 1.28 \\
6 & 0.82 & 0.20 & 0.60 & 1.12 & 0.73 & 1.44 & 0.30 & 1.04 & 1.30 \\
7 & 0.84 & 0.16 & 0.55 & 1.14 & 0.68 & 1.47 & 0.28 & 1.06 & 1.32 \\
8 & 0.86 & 0.14 & 0.52 & 1.14 & 0.63 & 1.48 & 0.34 & 1.03 & 1.26 \\
9 & 0.87 & 0.19 & 0.50 & 1.11 & 0.61 & 1.44 & 0.32 & 1.06 & 1.27 \\
10 & 0.88 & 0.22 & 0.50 & 1.12 & 0.59 & 1.41 & 0.30 & 1.07 & 1.29 \\
\hline
\end{tabular}


Table S10: Number of binding modes from ensemble docking with root mean squared deviation (RMSD) from the binding mode in the reference structure higher than $5 \AA$. Only heavy atoms of the ligand were considered for the RMSD calculation. No flex.: docking with rigid protein. Flex.: docking with flexible side chains (Ly53 and Glu71 for ligands 21, 23 and 24; Ile84 for ligand 26).

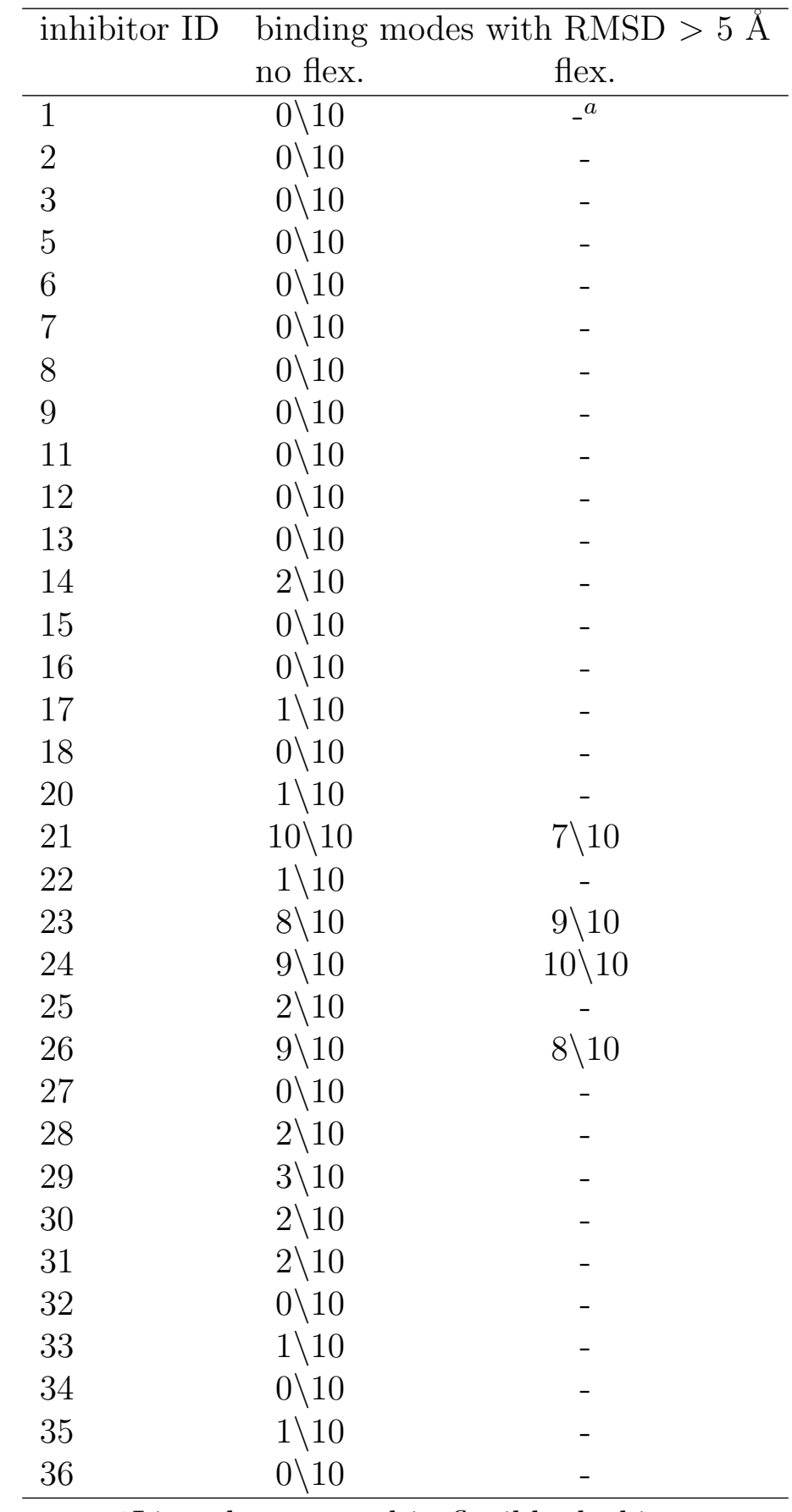

${ }^{a}$ Ligand not tested in flexible docking. 
Table S11: Statistical measures of previous studies which predicted $\mathrm{k}_{\text {off }}$ values for inhibitors of p38 MAP kinase. The table lists the coefficient of determination for the training and test sets $\left(R^{2} \operatorname{tr}\right.$ and $R^{2}$ te), the number of inhibitors in the test set $(\mathrm{N})$ and the computational method used.

\begin{tabular}{ccccc}
\hline reference & $\mathrm{R}^{2} \operatorname{tr}$ & $\mathrm{R}^{2}$ te & $\mathrm{N}$ & method \\
\hline 72 & $-^{a}$ & 0.88 & 8 & steered $\mathrm{MD}^{b}$ \\
75 & 0.82 & 0.82 & 10 & Volsurf \\
this work & 0.86 & 0.79 & 11 & COMBINE \\
74 & - & 0.64 & $41^{c}$ & local-scaled MD \\
73 & 0.72 & 0.56 & 6 & $\mathrm{MD}$ simulations $+\mathrm{IFP}^{d}+\mathrm{PLS}^{e}$ \\
76 & $0.60^{f}$ & 0.43 & 28 & random forest \\
\hline
\end{tabular}

${ }^{a}$ No training set was used. ${ }^{b} \mathrm{MD}$ : molecular dynamics. ${ }^{c}$ The test set included complexes with different types of kinases, not only p38 MAP kinase. ${ }^{d}$ Interaction fingerprints.

${ }^{e}$ Partial least squares regression. ${ }^{f}$ The $\mathrm{R}^{2} \operatorname{tr}$ value reported is for a training set including the 28 complexes used in the test set. 


\section{S1 Equations for coefficient of determination, average absolute error and root mean squared error}

The coefficient of determination $\left(\mathrm{R}^{2}\right.$, or $\mathrm{Q}^{2}$ for cross validation) was calculated as:

$$
R^{2}=\frac{\left[\sum_{i=1}^{N}\left(y_{i}-\langle y\rangle\right)\left(x_{i}-\langle x\rangle\right)\right]^{2}}{\sum_{i=1}^{N}\left(y_{i}-\langle y\rangle\right)^{2} \sum_{i=1}^{N}\left(x_{i}-\langle x\rangle\right)^{2}}
$$

where $\mathrm{N}$ is the number of data points, $y_{i}$ is the experimental value for point $\mathrm{i}, \mathrm{x}_{i}$ is the predicted value for point $\mathrm{i},\langle y\rangle$ is the average of experimental values and $\langle x\rangle$ is the average of predicted values.

The average absolute error (AAE) was calculated as:

$$
A A E=\frac{1}{N} \sum_{i=1}^{N}\left|x_{i}-y_{i}\right|
$$

The root mean squared error (RME) was calculated as:

$$
R M E=\sqrt{\frac{\sum_{i=1}^{N}\left(x_{i}-y_{i}\right)^{2}}{N}}
$$




\section{S2 Script for ligand superimposition}

For ligand superimposition, a custom script was written using Python 3.8 and the packages RDkit 2020.03.3 $3^{52}$ and MDAnalysis 1.0.0. ${ }^{53,54}$

"Reference system" refers to the coordinates of the protein of interest bound to a ligand, which will be used as a reference for the superimposition, and "new ligand" refers to the small molecule that will be superimposed onto the structure. The user must supply the reference system (variable "topology"), which should contain the fully prepared protein of interest with the reference ligand onto which the new ligand will be superimposed.

The reference system is parsed from a topology or coordinate file in a format supported by MDAnalysis (e.g. PDB format). The new ligand must be supplied as a RDkit mol object by the user (variable "ligand_new"). Hydrogens need to be present and the atoms in the ligand must have coordinates specifying their positions.

The reference ligand is selected from the universe object by using its residue name (variable "ligand_old"), saved as a PDB file and parsed to a mol object. RDkit is then used to calculate the Tanimoto similarity, find the maximum common fragment between the reference ligand and the new ligand, and extract it. The user can supply either additional atom indices or a completely new set of indices if the maximum common fragment is unsatisfactory. Both fragments are centered by subtracting the coordinates of their respective centers of mass from their atom coordinates. MDAnalysis is then used to calculate the rotation matrix that aligns the fragment in the new ligand optimally with the fragment in the reference ligand. Atoms are weighted according to their mass.

The new ligand is centered, translated by the center of mass of the reference ligand fragment and finally rotated using the calculated rotation matrix. The final output is the coordinates of the new ligand in PDB format, after superimposition.

In order to validate the ligand superimposition procedure, RMSDs between the superimposed ligands (ligands 3-15, 17-18 and 34-36) and the reference ligand (ligand 16) were 
computed using the heavy atoms of the maximum common substructure for the ligands compared and the web server ligRMSD. ${ }^{55}$ Table S12 shows that the RMSD values are low, as expected.

Table S12: Root mean squared deviations (RMSDs) between the superimposed ligands (ligands 3-15, 17-18 and 34-36) and the reference ligand (ligand 16). RMSDs were computed using the heavy atoms of the maximum common substructure for the ligands compared and the web server ligRMSD.

\begin{tabular}{lc}
\hline ligand ID & RMSD $(\AA)$ \\
\hline 3 & 0.16 \\
5 & 0.30 \\
6 & 0.31 \\
7 & 0.30 \\
8 & 0.31 \\
9 & 0.31 \\
11 & 0.30 \\
12 & 0.30 \\
13 & 0.18 \\
14 & 0.18 \\
15 & 0.35 \\
17 & 0.18 \\
18 & 0.30 \\
34 & 0.18 \\
35 & 0.20 \\
36 & 0.20 \\
\hline
\end{tabular}

